\title{
Morphology and Physiology of Single Neurons in the Medial Interlaminar Nucleus of the Cat's Lateral Geniculate Nucleus'
}

\author{
DENNIS RACZKOWSKI ${ }^{2}$ AND S. MURRAY SHERMAN ${ }^{3}$
}

Department of Neurobiology and Behavior, State University of New York at Stony Brook, Stony Brook, New York 11794

\begin{abstract}
Physiological studies have shown that the cat's retinogeniculocortical system is comprised of at least three parallel and independent pathways, the $W$-, $X$-, and $Y$-cell pathways. The morphological correlates of the constituent $W-, X-$, and $Y$-cells have been determined both in the retina and in the $A$ and $C$ laminae of the lateral geniculate nucleus. The aim of this study was to extend these structure/function relationships to neurons in laminae 1 and 2 of the medial interlaminar nucleus (MIN), which is a division of the cat's dorsal lateral geniculate nucleus. We used intracellular injection of horseradish peroxidase (HRP) into individual, physiologically identified MIN neurons. Since this procedure may yield an unrepresentative sample of MIN neurons, two controls were performed. First, Nissl staining showed that the soma sizes of intracellularly labeled cells were representative of those of all MIN cells. Second, retrograde labeling following HRP injections into the optic radiations or specific visual cortical areas showed that the intracellularly labeled MIN cells were representative of MIN relay neurons. Many of the retrogradely labeled cells were so well filled that their entire dendritic arbors were revealed.

Of 70 MiN neurons recorded physiologically, 22 were injected with HRP and successfully recovered. We also completely labeled the somata and dendrites of 114 MIN neurons from HRP injections into the optic radiations and retrogradely labeled 165 MIN neurons by injection of HRP into visual cortical areas. Our sample of intracellularly injected neurons, which were all Y-cells, were morphologically representative of all MIN relay cells. We thus conclude that laminae 1 and 2 of the MIN contain a nearly homogeneous population of $Y$ cells with properties essentially identical to those of $Y$-cells in the $A$ and $C$ laminae of the lateral geniculate nucleus. When viewed in the coronal plane, MIN projection neurons typically exhibited oval or elongated somata. In the medial and ventral parts of the MIN, these somata were smaller and more flattened. MIN soma sizes extended over the full range of those seen in the A laminae. Dendritic arbors of most MIN relay neurons radiated in a fairly spherical fashion. In the
\end{abstract}

Received December 10, 1984; Revised February 28, 1985; Accepted March 15, 1985

\footnotetext{
${ }^{1}$ We thank David Tessin and James R. Wilson for assistance in some of these experiments and Joan Sommermeyer, Angela Gero, and Patricia Palam for their expert technical assistance. This research was supported by USPHS grant EYO3038

${ }^{2}$ Current address: Department of Anatomy, Duke University Medical Center, Box 3011, Durham, NC 27706

${ }^{3}$ To whom correspondence should be addressed.
}

medial and ventral parts of the MIN, however, dendrites were oriented in a more bipolar fashion, but intermediate forms between spherical and bipolar arbors were also common. Dendrites of MIN projection neurons were typically smooth; most primary dendrites were straight, but secondary dendrites were more variable in structure. Some dendrites crossed borders between laminae 1 and 2; some crossed from the MIN to the A or C laminae or to the lateral posteriorpulvinar complex. Dendritic appendages were rare and usually simple, spine-like processes. Occasionally, more complex appendages clustered near dendritic branch points. Axons of these MIN neurons followed a direct trajectory out of the nucleus, although intrageniculate collaterals were occasionally seen. Only one axon in our sample innervated the perigeniculate nucleus. We found no physiological or morphological evidence for more than the one neuronal $Y$-cell class in laminae 1 and 2 of the MIN.

The medial interlaminar nucleus (MIN) is a conspicuous subdivision of the cat's dorsal lateral geniculate nucleus. The MIN lies medial to the $A$ and $C$ laminae, serves as a direct relay of visual afferents from the retina to the visual cortex, contains a complete representation of the visual field (Kinston et al., 1969; Sanderson, 1971; Rosenquist et al., 1974; Guillery et al., 1980; Tong et al., 1982; Raczkowski and Rosenquist, 1983; Lee et al., 1984), and is organized into three main laminae. Laminae 1 and 3 are innervated by the contralateral eye, and lamina 2 is innervated by the ipsilateral eye (Guillery et al., 1980). Lamina 3, which is innervated by the contralateral temporal retina and thus represents the ipsilateral visual field, is located anteriorly and was not studied in these experiments; laminae 1 and 2 form a reasonably matched pair, each representing one eye, and these laminae form the basis of this paper. Large caliber, fast conducting retinal axons innervate laminae 1 and 2 , and virtually all neurons recorded here are $Y$-cells, with physiological properties similar to those of geniculate $Y$-cells of the $A$ and $C$ laminae (Mason, 1975; Palmer et al., 1975; Kratz et al., 1978; Guillery et al., 1980; Sur and Sherman, 1982; Bowling and Michael, 1984). However, some neurons with $W$ - and $X$-cell properties also have been reported in the MIN (Dreher and Sefton, 1979). The cortical projection of MIN neurons is quite extensive, including areas 17, 18 19 , and two areas located along the medial bank of the lateral suprasylvian sulcus, areas AMLS and PMLS (Rosenquist et al., 1974 Tong et al., 1982; Raczkowski and Rosenquist, 1983).

In an effort to extend our understanding of the MIN and its relay of visual information to cortex, we investigated the relationships of the morphological features of MIN neurons with their physiological properties and projection patterns to visual cortex. In this report, we determined directly the morphology of MIN neurons by intracellular injections of HRP into individual, physiologically classified neurons.

To control for sampling biases of the intracellular injections, we used 
other anatomical techniques (Nissl staining and retrograde horseradish peroxidase (HRP) labeling) to verify the representative nature of the intracellularly filled cells. From these data, we conclude that laminae 1 and 2 of the MIN are comprised exclusively or nearly so of $Y$-cells that exhibit considerable morphological variability; certain morphological features are similar to and others different from those of $Y$-cells in the $A$ and $C$ laminae. A preliminary report of some of these data recently appeared (Raczkowski and Sherman, 1983).

\section{Materials and Methods}

General electrophysiological methods. Most of the methods used in these experiments have been described in detail previously; thus, only a brief outline of these will be provided. Further details of the surgical preparation, visual stimulation, electrophysiological recording techniques, histological methods, and analytical procedures can be found elsewhere (Kratz et al., 1978; Friedlander et al., 1981; Mangel et al., 1983; Stanford et al., 1983). Only the retrograde labeling of MIN neurons is considered more fully, because we have not previously published the methods for this. Experiments were performed on adult cats weighing between 2.0 and $4.0 \mathrm{~kg}$. They were anesthetized (initially with halothane for all surgical procedures and subsequently with a combination of $\mathrm{N}_{2} \mathrm{O} / \mathrm{O}_{2}$ and barbiturate), paralyzed, and prepared for visual neurophysiology. Bipolar stimulating electrodes were placed across the optic chiasm and, in some experiments, into the visual cortex. Recording electrodes consisted of fine-tipped, HRP-filled micropipettes, which allowed extracellular and intracellular recording as well as intracellular HRP iontophoresis. Visual stimuli consisted of bright and dark targets presented on a frontal tangent screen and of gratings that were sinusoidally modulated in space and time and presented on a cathode ray tube. A standard battery of tests was used to identify geniculate $W-, X$ - and Y-cells.

General anatomical methods. Histological methods for HRP histochemistry, autoradiography, Nissl staining, and morphometry have been previously described (Kratz et al., 1978; Friedlander et al., 1981; Stanford et al., 1983). Autoradiography combined with HRP histochemistry was performed in four animals following injection of $0.1 \mathrm{mCi}$ tritiated leucine into the vitreous of one eye. This allowed us to detect the "hidden lamination" of the MIN and compare this to the extent of dendritic arbors of MIN neurons (cf. Kratz et al., 1978; Stanford et al., 1983).

Retrograde filling from the optic radiations with HRP. Cats were anesthetized with sodium pentobarbitol $(40 \mathrm{mg} / \mathrm{kg}$ ) and an insulated tungsten electrode was lowered into the brain. Light-evoked responses were recorded, and the region of the optic radiations immediately above the lateral geniculate nucleus was identified for HRP injections. We removed the electrode and replaced it with a $1.0-\mu$ l syringe containing a solution of $10 \% \mathrm{HRP}$. Once the syringe needle was properly positioned, $0.1 \mu \mathrm{l}$ of the HRP solution was expelled over a 5 -min period.

Retrograde labeling from cortex with HRP. We also studied the morphology of MIN neurons retrogradely labeled from injections of HRP into specified areas of cortex and compared this with the intracellularly and bulk-filled samples. This was actually a re-analysis of previously published data (Raczkowski and Rosenquist, 1983). MIN neurons retrogradely labcled with HRP following these cortical injections were analyzed chiefly in terms of soma size and location.

Statistics. Unless otherwise stated, the Mann-Whitney $U$ test was used for all statistical comparisons.

\section{Results}

We obtained recordings from 70 neurons in laminae 1 and 2 of the MIN. Of these 70, 65 were $Y$-cells, 3 were $X$-cells, and 2 were unclassified. The $X$-cells had receptive fields within a few degrees of the vertical meridian and thus may have been located at the medial edge of the A laminae rather than within the MIN. The unclassified cells had fast conducting axons and a phasic response to a stimulus of appropriate standing contrast ( $Y$-cell features), but they summed luminance changes in a linear fashion (an $X$-cell feature). It is possible that these unclassified neurons were $Y$-cells with weak or undetectable nonlinear responses (Mangel et al., 1983). No $W$-cells were unambiguously identified in our population. Twentytwo of the MIN neurons, all identified as Y-cells, were successfully impaled, injected with HRP, and analyzed morphologically. Of these 22, 17 were selected for detailed light microscopic study on the basis of relatively complete staining of somata and dendrites (see Table I). A cell was regarded as completely stained if its dendritic arbor was darkly labeled, with abrupt ending of the label at apparent terminations of fine dendrite processes. The remaining 5 neurons were incompletely filled beyond the soma and proximal dendrites, with gradual diminution of the label at more distal dendritic locations. Morphological data from these 5 cells were limited to soma size, shape and location. Each of the completely stained neurons had an axon that emerged either from the soma or a primary dendrite, and several of these axons could be traced for several millimeters into the optic radiations.

\section{Electrophysiological properties}

Recording electrodes were inserted at an angle $30^{\circ}$ to the vertical in the coronal plane, so that the electrode moved ventromedially through the lateral geniculate nucleus (Kratz et al., 1978). Consequently, the electrode encountered neurons in the $A$ and often the $C$ laminae before moving into the MIN. Due to our reliance on receptive field location in the $A$ laminae and field reversals to locate the MIN, our electrodes only rarely passed through the ipsilateral hemifield representation in lamina 3 of the MIN, and no single neurons were studied with receptive fields more than a degree or so in the ipsilateral hemifield.

No physiological differences were evident between the entire population of MIN Y-cells encountered and the subpopulation that was analyzed morphologically. Figure 1 shows how these two populations compare in terms of latency to optic chiasm stimulation and receptive field size, and no differences were seen on these measures $(p>0.1)$. Although receptive field size varies with eccentricity (Kratz et al., 1978; Dreher and Sefton, 1979), the two populations were well matched for eccenlricity, and a closer analysis of the data in Figure $1 B$ revealed no difference between populations in their eccentricity/center size relationship (not shown). We conclude that the sample of MIN cells from which our morphological data derive are reasonably representative of MIN Y-cells in laminae 1 and 2.

\section{Morphological properties}

\section{Cells filled retrogradely with HRP}

From our analysis of somata, dendritic branching patterns, and dendritic appendages of MIN projection neurons labeled by injecting HRP into the optic radiations (Fig. 2), one broad class of projection neurons could be identified in the MIN. This contrasts with the three broad morphological classes of projection neuron described for the A and C laminae (Guillery, 1966; Fricdlander et al., 1981; Hitchcock and Hickey, 1983; Stanford et al., 1983).

Somata and dendrites. Figure 3 summarizes the soma size distribution of the MIN neurons retrogradely filled with HRP placed into the optic radiations. The somata were typically oval or elongated in shapc. In the medial and ventral part of the MIN, the somata tended to be smaller and more flattened or fusiform in shape compared to somata located in more dorsal and lateral regions (Figs. 4 and 5).

Three to 10 primary dendrites issued at irregular intervals from the somata of these labeled neurons. The primary dendrites were typically smooth (i.e., free of appendages). In some neurons, dendrites extended from the somata in a radial fashion and occupied fairly spherical zones. Some of these dendrites crossed laminar borders, either medially out of the lateral geniculate nucleus or laterally into the $\mathrm{A}$ and $\mathrm{C}$ laminae. In some other neurons, especially in the medial and ventral parts of the MIN, dendrites radiated in a more bipolar fashion, forming a disc-shaped arbor with a short axis roughly parallel to the laminar borders of the MIN. Dendrites crossing between laminae 1 and 2 within the MIN are dealt with below in a consideration of autoradiographic material

Primary dendrites of MIN projection neurons usually followed a relatively straight course away from the soma. Dendritic branching typically produced only two fairly straight daughter branches. These dendrites ofien exhibited alternating constrictions and dilations, giv- 
Figure 1. Comparison between a subpopulation of $22 \mathrm{HRP}$-filled cells and all 70 recorded MIN cells in terms of latency to optic chiasm stimulation and receptive field center diameter. $A$. Frequency histogram of latency to electrical stimulation of the optic chiasm. $B$, Frequency histogram of receptive field center diameter.
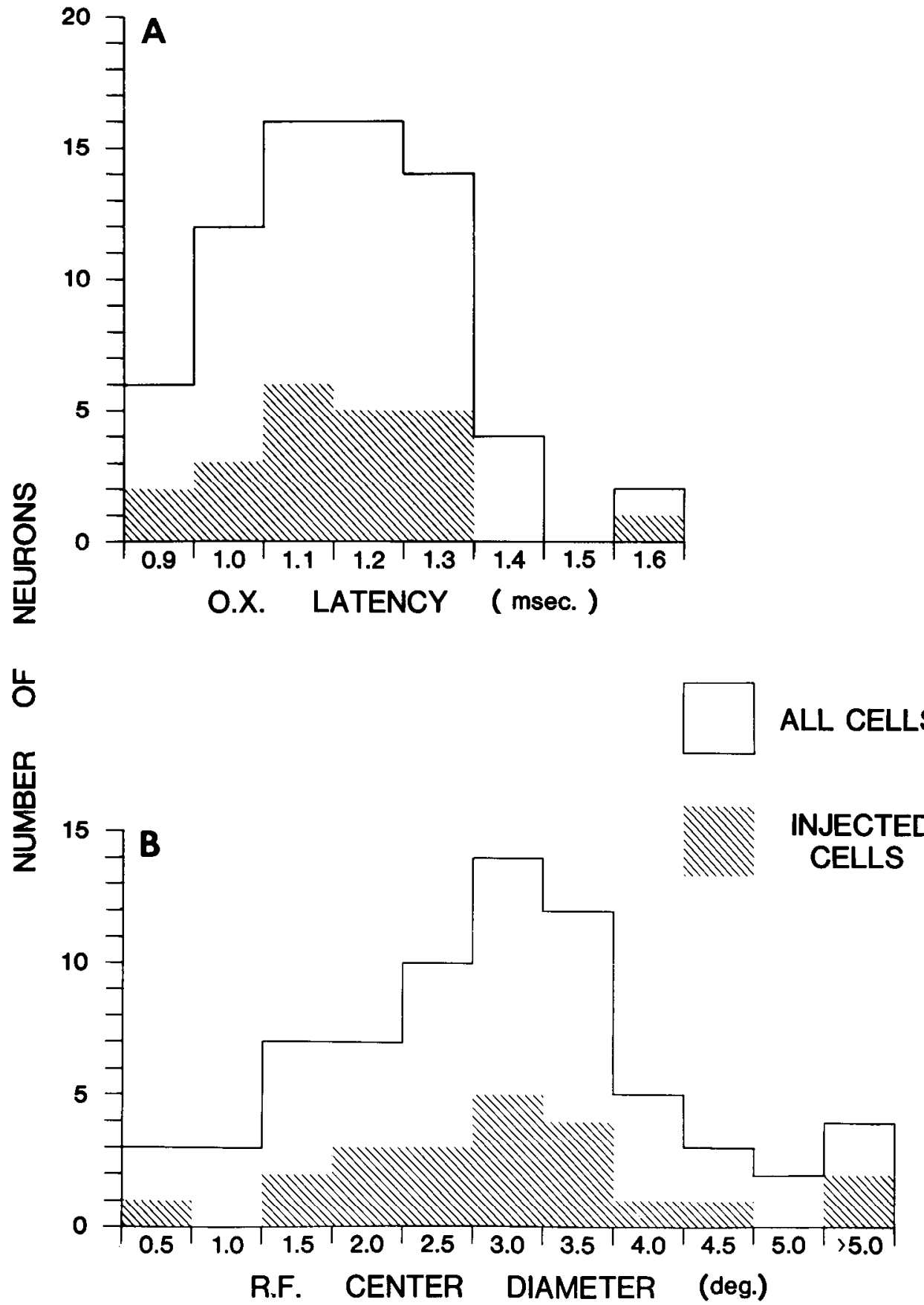

ing the dendrite a varicose appearance. The terminal dendritic branch usually tapered to a fine tip with no visible swelling.

Dendritic appendages. On the whole, dendritic appendages of MIN projection neurons were rare and, when present, were simple spine-like processes. Many dendrites were virtually bare. On other dendrites, lengths up to $100 \mu \mathrm{m}$ were completely free of appendages, but multiple appendages could then be found in scattered clusters (see also below). The number of appendages seen on dendrites of MIN relay neurons was comparable to that observed for class $1 Y$-cells in the geniculate $A$ and $C$ laminae and much less than that seen on class 2 or $3 X$-cells in the A laminae or on class 4 W-cells in the C laminae (Friedlander et al., 1981; Stanford et al., 1983)

\section{Cells filled intracellularly with HRP}

Overview. Generally, the morphology of our sample of intracellularly filled MIN neurons was reasonably homogeneous and rather similar to that of class $1 \mathrm{Y}$-cells in the $\mathrm{A}$ and $\mathrm{C}$ laminae. Table I summarizes various parameters of the intracellularly filled cells that are further illustrated below. Figures 6 to 8 illustrate two MIN Y-cells with typical class 1 morphology. Their somata were fairly large and their dendrites were thick and fairly straight. However, beyond the primary branch point, dendrites often showed alternating constrictions and swellings that gave the dendrite a varicose or beaded appearance. Those dendritic characteristics are further demonstrated with photomicrographs in Figure 7. The dendrites occupy a more or less circular zone, and some crossed from the MIN to the C laminae.

Figure 9 shows an unusual class $1 \mathrm{Y}$-cell. The large soma and straight, smooth dendrites with rare and simple appendages are typical features of class $1 \mathrm{Y}$-cells in the $\mathrm{A}$ and $\mathrm{C}$ laminae. However, this cell's bipolar dendritic arbor differs from the spherical arbors of these other Y-cell types (Friedlander et al., 1981; Stanford et al., 1983).

The three MIN Y-cells illustrated in Figures 6 to 9 are similar to each other, primarily with regard to soma size, morphology of 

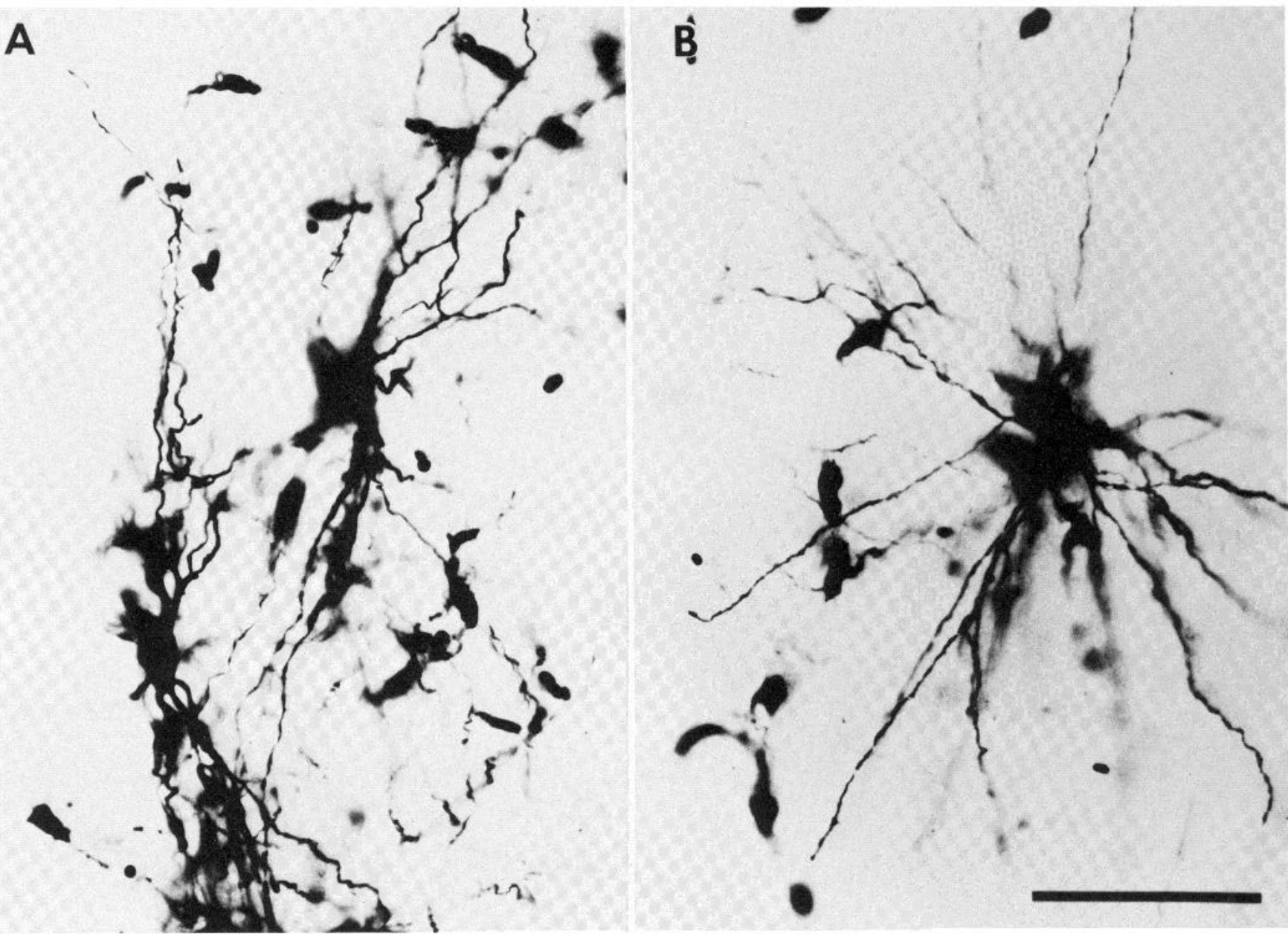

Figure 2. $A$ and $B$ are photomicrographs of MIN neurons retrogradely labeled after an injection of HRP into the optic radiations. Note that the dendrites are relatively straight and appendage free. Scale bar, $100 \mu \mathrm{m}$ (for $A$ and $B$ ).

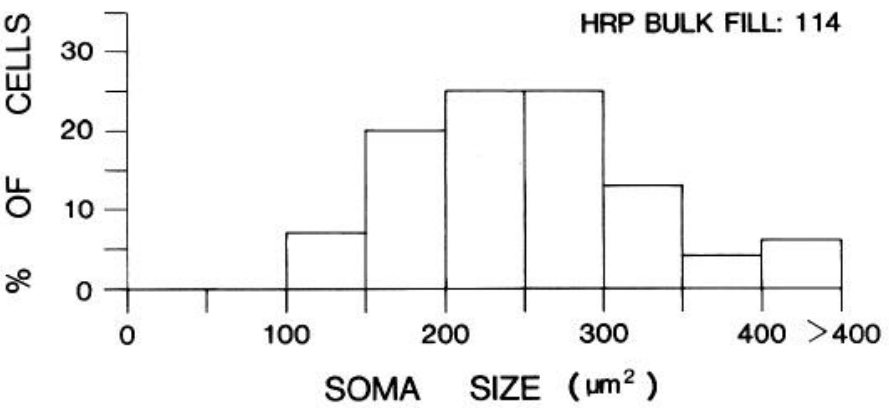

Figure 3. Soma size distribution of $114 \mathrm{MIN}$ relay neurons retrogradely labeled by injecting HRP into the optic radiations. Compare this distribution with those in Figure 11.

individual dendrites, and number and appearance of dendritic appendages. They differ mainly in the number of dendrites and the degree of orientation of the dendritic arbor. As noted below, MIN cells thus appear to be a single morphological class of neurons with considerable variability in the shape of somata and dendritic arbors. The variability may largely reflect an adaptation of neuronal shape to the geometry of the MIN. In partial support of this conclusion, Figure 10 illustrates four additional intracellularly labeled MIN Y-cells and their locations in the MIN. The variability in the degree of polarization of the dendritic arbor (e.g., spherical versus bipolar) seems to be related to soma location within the MIN.
Somata. The histogram in Figure $11 A$ shows the soma size distribution of the 22 MIN Y-cells that were filled intracellularly with HRP. The distribution is unimodal and closely matches that seen in Figure $3(p>0.1)$. However, some of these $Y$-cells in the MIN are smaller than any reported for the $\mathrm{A}$ and $\mathrm{C}$ laminae (Friedlander et al., 1981; Stanford et al., 1983).

We were concerned with the possibility of substantial numbers of W- and X-cells in laminae 1 and 2 of the MIN (Kratz et al., 1978; Dreher and Sefton, 1979; Rowe and Dreher, 1982), and we thus needed to determine whether the MIN Y-cells stained by intracellular injection were a representative sample of MIN neurons. The representative nature of the intracellularly filled cells is supported by the abovementioned comparison of Figures 3 and $11 A$. It is also supported by Figure $11 B$, which shows the size distribution of Nissstained MIN somata obtained from the same tissue in which HRP. filled neurons were found. Somata were measured across the width of the nucleus in the middle third (anteroposteriorly and dorsoventrally) of the MIN, and little interanimal variation was evident in this measure. The distributions for HRP-filled and Nissl-stained somata are rather similar $(p>0.1)$.

Figure $11, C$ and $D$, which shows the soma size distribution of MIN relay neurons retrogradely labeled by injecting HRP into various cortical areas innervated by the MIN, further supports the lack of sampling bias among our intracellularly labeled cells. For this retrograde labeling, both the cortical area and the locus of injection were identified by physiological recording (see "Materials and Methods" and Raczkowski and Rosenquist, 1983). No significant difference was seen in soma sizes of neurons labeled from different cortical 
Figure 4. Drawing tube tracings from single $100-\mu \mathrm{m}$-thick sections of retrogradely labeled MIN relay cells following injection of HRP into the optic radiations. The number adjacent to each tracing refers to the position of the cell body within the MIN as indicated in the inset. Note the round to oval somata, the multiple straight dendrites, and the relative paucity of dendritic appendages. Scale bar, $50 \mu \mathrm{m}$.

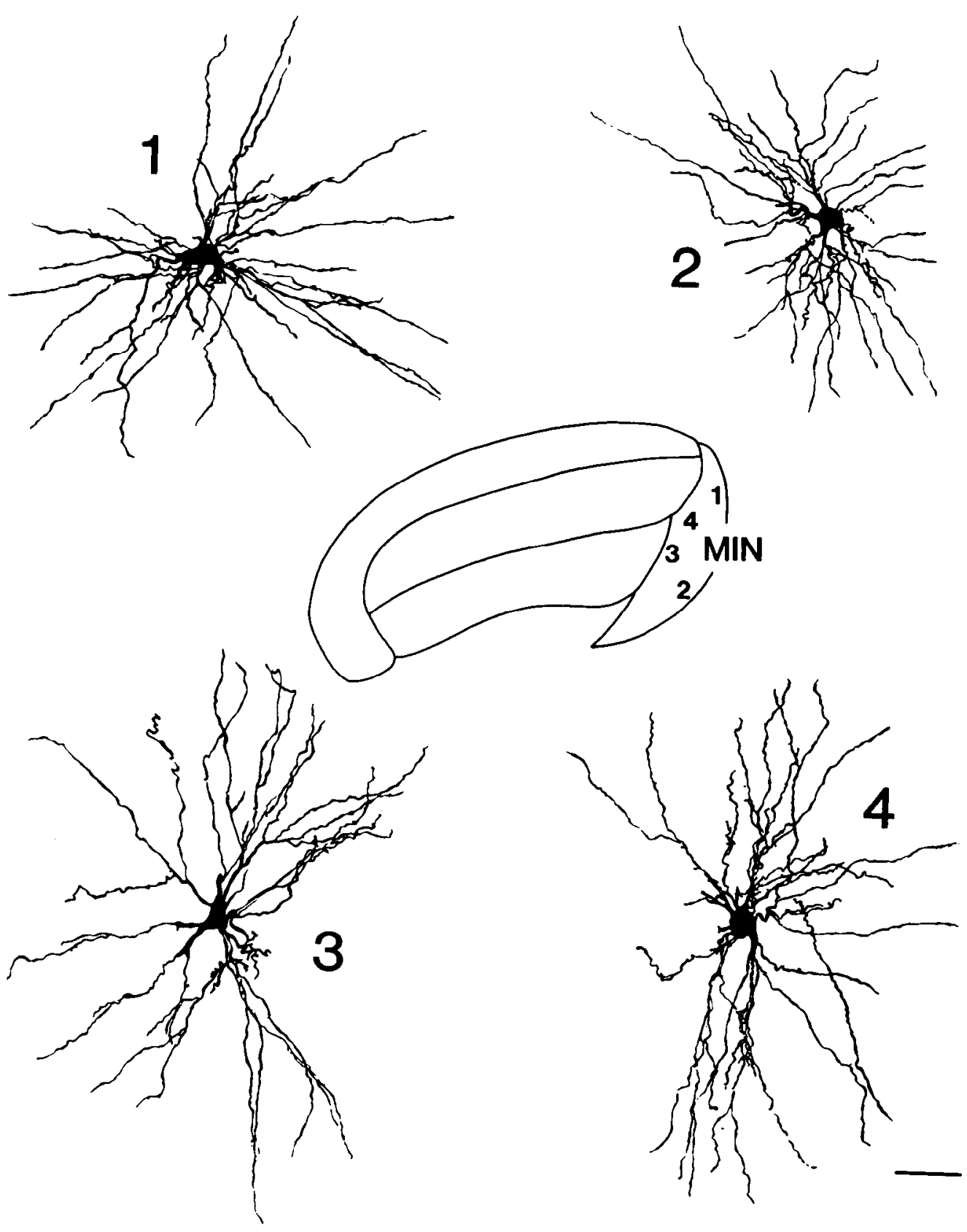

areas, and the overall size distribution of retrogradely labeled somata is comparable to that of our intracellularly filled or Nissl-stained distributions $(\rho>0.1)$.

Dendrites and appendages. From Figure 6 and Figures 8 to 10, it is evident that dendrites of MIN Y-cells possessed a number of characteristic features; some of these features are further illustrated in Figure 12. Primary dendrites were typically straight and smooth (Fig. 12A), but secondary dendrites were more variable in their appearance. Some of the latter were relatively straight, whereas others exhibited alternate swellings and constrictions. Depending on these constrictions, secondary dendrites took on a varicose (Fig. 12B) or beaded (Fig. 12, C and D) appearance.

The simplest of the dendritic appendages seen on these cells were single hair-like processes with no terminal swelling (Fig. 13A). More commonly, appendages consisted of spherical swellings placed close to the dendrite (Fig. 13, $B$ and C). Often no stalk was visible (Figure 13B), but sometimes a short, thin stalk could be seen (Fig. 13C). Occasionally, spherical or ovoid, grape-like appendages occurred in clusters, near dendritic branch points (Fig. 13D).

Dendritic arbors. The geometry of dendritic arbors of the HRP- stained MIN Y-cells exhibits considerable heterogeneity. Some neurons had a radiate branching pattern; for other cells, the dendrites were oriented in a more or less bipolar fashion. We examined the variability in the degree of dendritic orientation more systematically by means of a modified Sholl ring analysis. This analysis was carried out previously (Friedlander et al., 1981; Stanford et al., 1983) on HRP-filled neurons in the $A$ and $C$ laminae by placing a series of five concentric rings separated by $50 \mu \mathrm{m}$ on a reconstruction of a neuron, with the rings centered on the soma. These rings were divided into quadrants oriented in such a way that two were perpendicular and two were parallel to the laminar borders. The number of intersections made between the dendrites and rings in each quadrant was then counted.

One of the difficulties in applying this approach to our sample of HRP-filled Y-cells in the MIN is that laminae 1 and 2 are irregular in shape and curvature, so that we cannot easily orient the quadrants with respect to these laminae for such a Sholl ring analysis. Since we wished only to measure anisotropy of the dendritic arbors, we divided the concentric rings into eight equal compartments and counted the number of intersections made in each between den- 

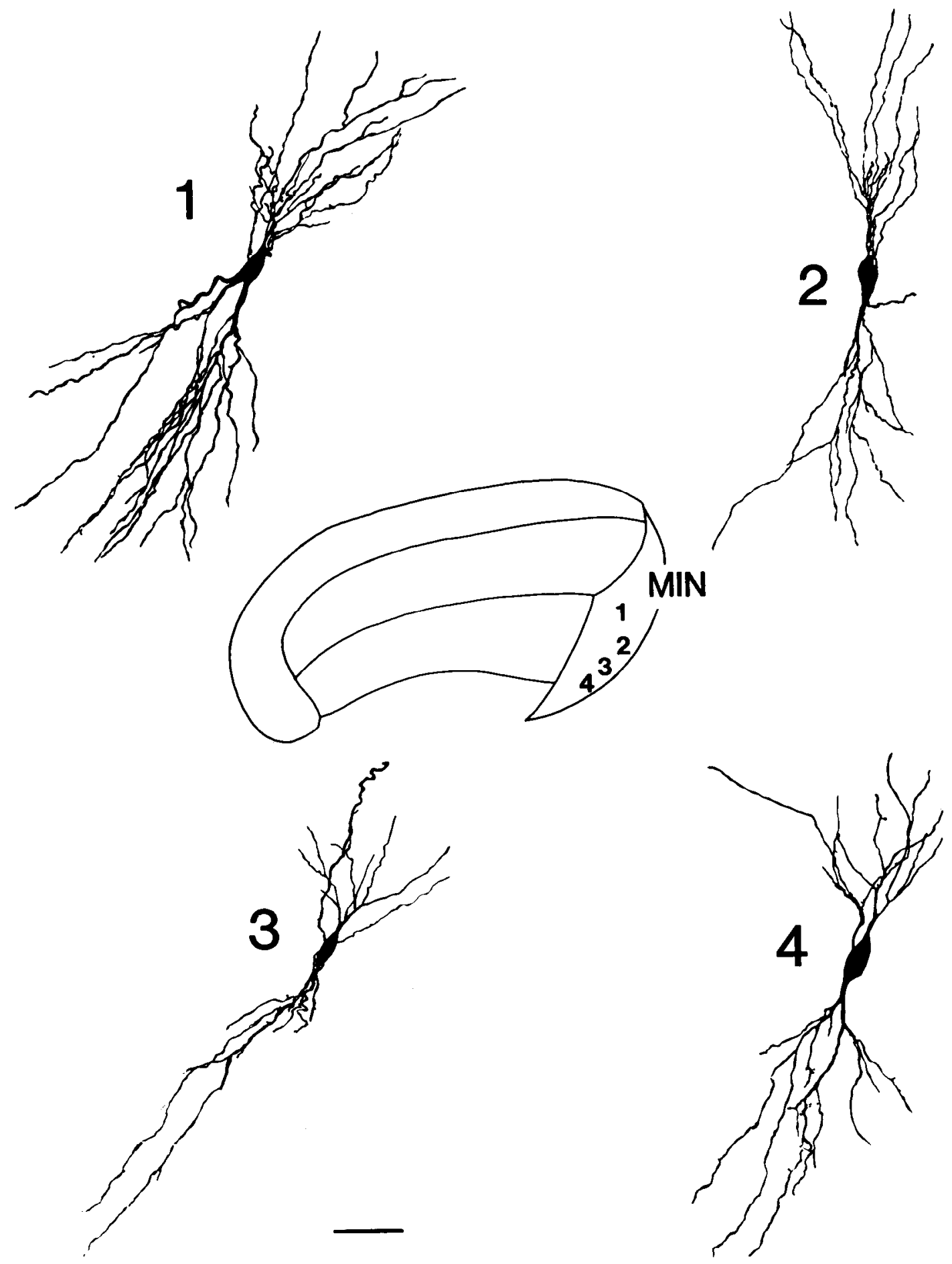

Figure 5. Drawing tube tracings of retrogradely labeled MIN relay neurons as in Figure 4. Note the extreme fusiform shape of the somata and the bipolar orientation of the dendritic arbors. Scale bar, $50 \mu \mathrm{m}$.

drites and rings. Two of these neighboring compartments thus equal a quadrant. To obtain what we term a "symmetry ratio," we identified which opposite quadrants comprised of two opposite pairs of compartments contained the most intersections. Four possibilities exist, and they are illustrated in the inset in Figure 14. We divided the number of intersections contained in the shaded compartments by the lesser intersections contained in the remaining (open) compartments. In Figure 14, these values are plotted along the abscissa. Along the ordinate is plotted the number of cells with a given symmetry ratio. Neurons which possess radial dendritic branching patterns have a symmetry ratio near 1.0; neurons with strongly bipolar dendritic arbors have a symmetry ratio much higher than 1.0 . These ratios show considerable variability, but no evidence of more than one continuous morphological type is evident from this analysis. We thus conclude that the spherical and bipolar dendritic arbors represent ends of a continuum rather than distinct classes of MIN neuronal type.

Translaminar dendrites. Above, we showed examples of MIN Ycells with at least some dendrites that crossed into the neighboring A or C laminae or into the lateral posterior-pulvinar complex. Because 
TABLE I

Properties of illustrated MIN Y-cells

\begin{tabular}{|c|c|c|c|c|c|c|}
\hline Cell Illustrated by Figure No. & $\begin{array}{c}\text { Optic Chiasm } \\
\text { Latency } \\
\text { (msec) }\end{array}$ & $\begin{array}{l}\text { Center } \\
\text { Type }\end{array}$ & $\begin{array}{c}\text { Receptive Field } \\
\text { Center Size } \\
\text { (degrees) }\end{array}$ & $\begin{array}{c}\text { Receptive Field } \\
\text { Eccentricity } \\
\text { (degrees) }\end{array}$ & $\begin{array}{l}\text { Dominant } \\
\text { Eye }\end{array}$ & $\begin{array}{c}\text { Soma } \\
\text { Size, } \mu \mathrm{m}^{2}\end{array}$ \\
\hline $6 ; 7 \mathrm{~A}, \mathrm{~B}, \mathrm{C} ; 13 \mathrm{~B}$ & 1.3 & OFF & 4 & 12.0 & $\rho^{a}$ & 181.0 \\
\hline $8 ; 12 C ; 13 C ; 16 A 3, B, C$ & 1.3 & ON & 2 & 10.0 & C & 385.6 \\
\hline 9 & 1.3 & OFF & 2.5 & 17.5 & C & 167.8 \\
\hline $10 \mathrm{~A} ; 12 \mathrm{D} ; 13 \mathrm{D}$ & 1.1 & OFF & 3.0 & 11.0 & 1 & 178.0 \\
\hline $10 \mathrm{~B} ; 12 \mathrm{~B} ; 16 \mathrm{~A} 2, \mathrm{~B}$ & 1.2 & ON & 5.0 & 15.0 & C & 241.0 \\
\hline $10 \mathrm{C} ; 16 \mathrm{A1}$ & 1.2 & OFF & 2.0 & 22.0 & $\mathrm{C}$ & 309.0 \\
\hline 10D & 0.9 & OFF & 10.0 & 25.0 & $\mathrm{C}$ & 327.0 \\
\hline $12 \mathrm{~A} ; 15$ & 1.3 & OFF & 2.0 & 14.0 & C & 761.0 \\
\hline
\end{tabular}

${ }^{2}$ I, ipsilateral; C, contralateral.

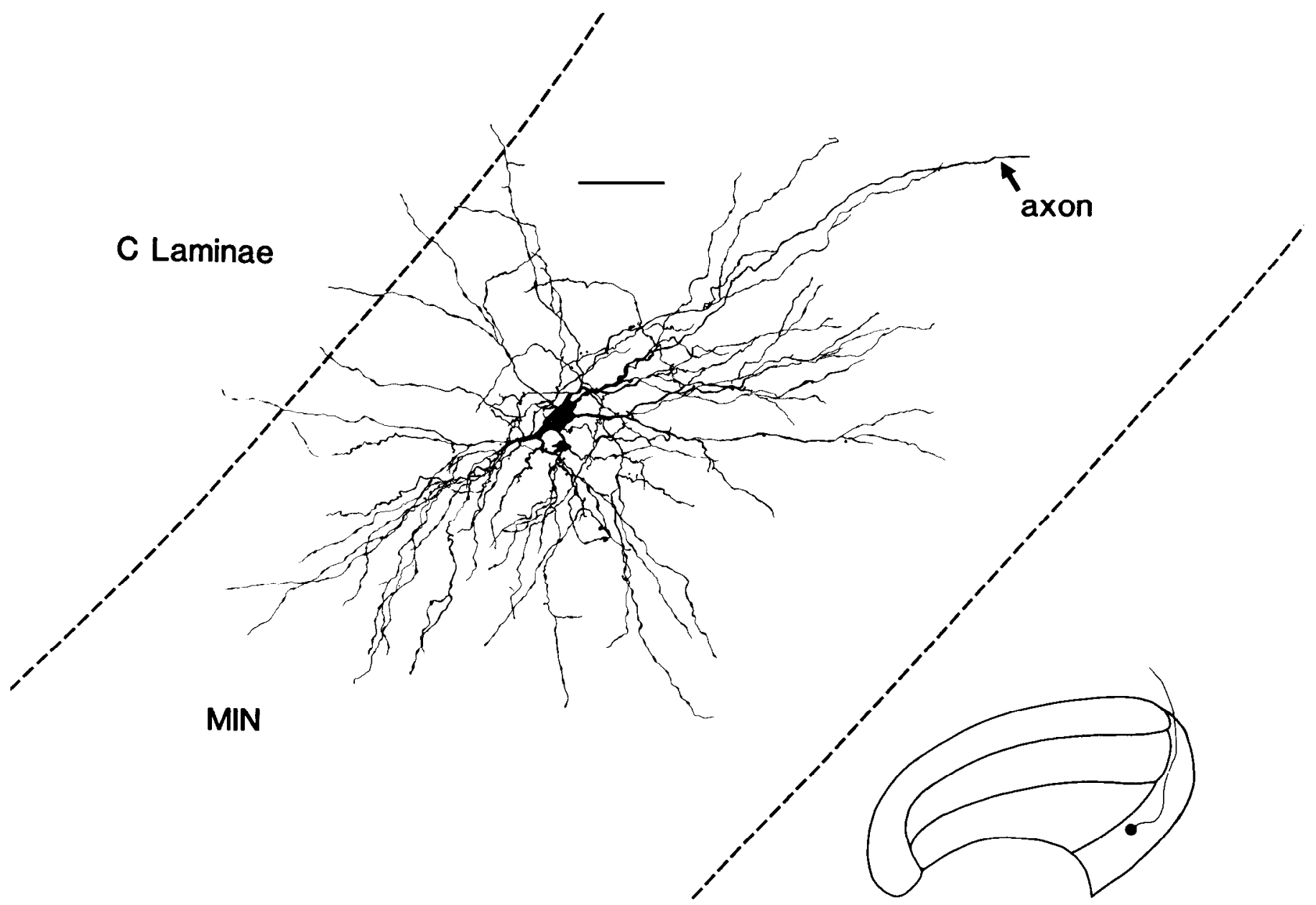

Figure 6. Drawing tube tracings of intracellularly HRP-stained MIN Y-cell reconstructed from adjacent 100- $\mu$ m-thick coronal sections. In this and similar figures that follow, the inset drawing indicates the position of the soma and the course of the axon relative to laminar borders. Dashed lines are used to show these same borders on the main drawing. Note the elongated soma, the thin, sinuous dendritic segments, and the paucity of dendritic appendages. Several dendrites crossed into the C laminae. Scale bar, $50 \mu \mathrm{m}$ for main drawing; $1 \mathrm{~mm}$ for inset.

individual laminae in the MIN cannot be readily visualized in Nissl preparations, it was not clear whether any dendrites of MIN Y-cells also crossed these laminar borders (i.e., between laminae 1 and 2).

To address this question, we identified the pattern of retinal input to the MIN in several animals by injecting the vitreous of one eye with tritiated leucine prior to the recording session. One of our intracellularly labeled MIN Y-cells was obtained from these autoradiographic experiments, and a reconstruction of the neuron is illustrated in Figure 15. A series of $50-\mu$ m thick sections just in front and in back of the sections containing the injected neuron were processed for autoradiography. (The tissue containing the labeled neuron was dehydrated and embedded in plastic in preparation for electron microscopy.) By aligning blood vessels and other tissuc artifacts, we were able to place laminar borders on the reconstruction of the neuron. A comparison of the cell reconstruction with the autoradiographic label revealed that, although the soma and many of its dendrites were located in lamina 1 of the MIN, which was expected due to the cell's receptive field being associated with the contralateral eye, at least a few dendrites crossed into lamina 2. Some of these dendrites were sufficiently close to the surface of the section and, thus, to the autoradiographic emulsion in the adjacent section, that they were within $10 \mu \mathrm{m}$ of the emulsion; we are particularly 

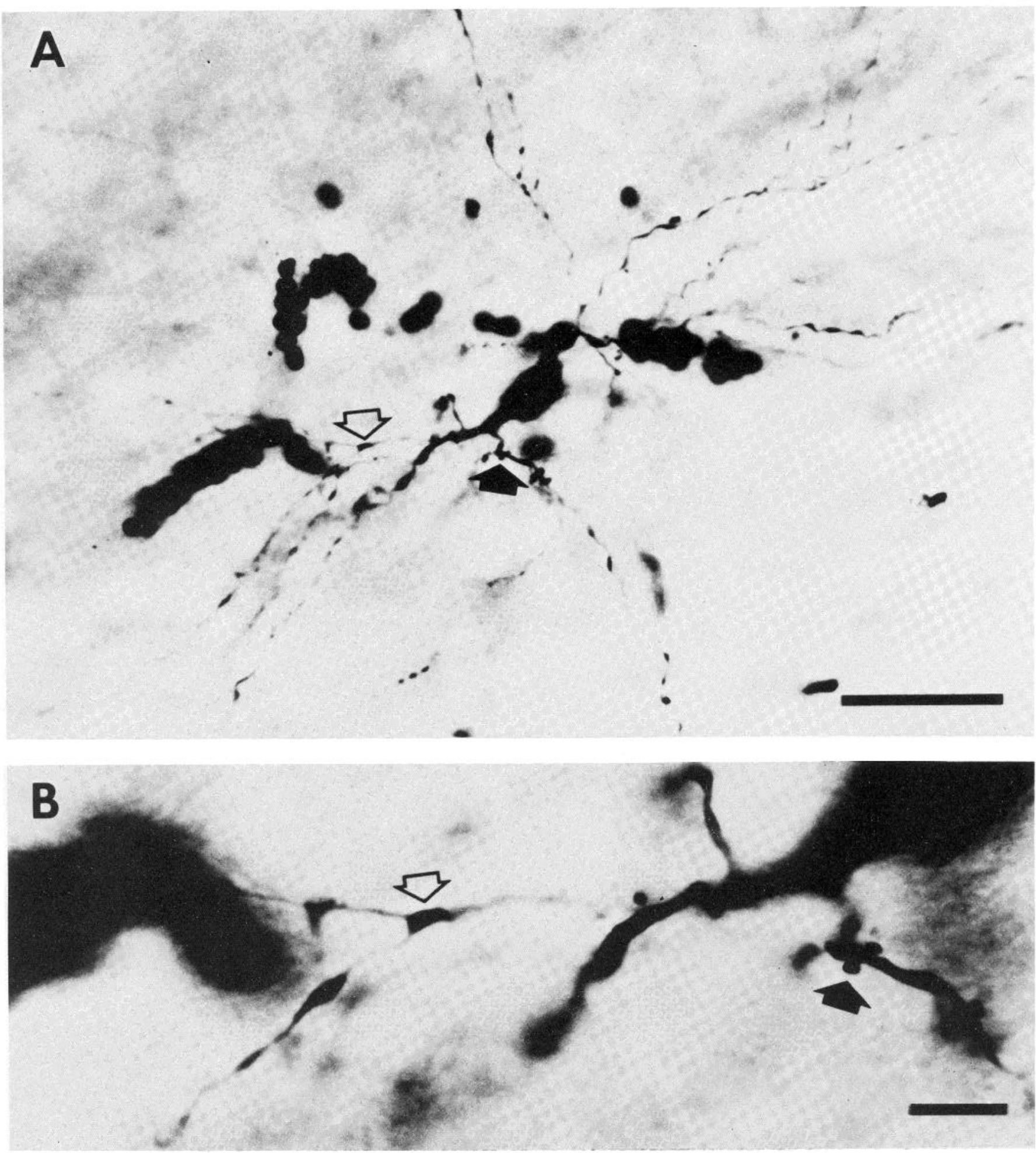

Figure 7. Photomicrographs of the MIN Y-cell drawn in Figure 6. A, Lower power view of the MIN Y-cell. Scale bar, $25 \mu \mathrm{m}$. B, Higher power view of dendrites and appendages of the cell in $A$. Scale bar, $5 \mu \mathrm{m}$. The solid arrows in $A$ and $B$ denote simple, spherical dendritic specializations, and the open arrows indicate a branch point beyond which are found dendritic varicosities.

confident that these dendrites cross from lamina 1 into lamina 2. Other dendrites extended across the border of the MIN into both laminae $A 1$ and $C$. Previous studies have shown that $W$ - and $Y$-cells, but not $\mathrm{X}$-cells, in the $\mathrm{A}$ and $\mathrm{C}$ laminae have dendrites that cross laminar borders (Friedlander et al., 1981; Stanford et al., 1983). We now extend this finding to at least some $\mathrm{Y}$-cells in the MIN.

Axons. Filled axons were traced from every well stained neuron in our sample. Usually the axon emerged from the soma, but sometimes it originated from a primary dendrite. Many of these axons could be followed into the optic radiations. The trajectories of these axons, unlike those of relay neurons in the $A$ and $C$ laminae (Friedlander et al., 1981; Stanford et al., 1983), were fairly straight and direct. Some of the trajectories are illustrated in Figure 16.

Axon collaterals were rarely observed in our material. Of the 17 
Figure 8. Drawing tube tracings of an MIN Y-cell intracellularly filled with HRP. The dendrites of this neuron are relatively smooth and oriented in a radially symmetric fashion. The axon issued two intrageniculate collaterals within the MIN and coursed through the perigeniculate nucleus, where additional collaterizations occurred. These axon collaterals $(*)$ are drawn at higher magnification in Figure 16, $B$ and $C$. Scale bar. $50 \mu \mathrm{m}$ for main drawing; $400 \mu \mathrm{m}$ for inset.

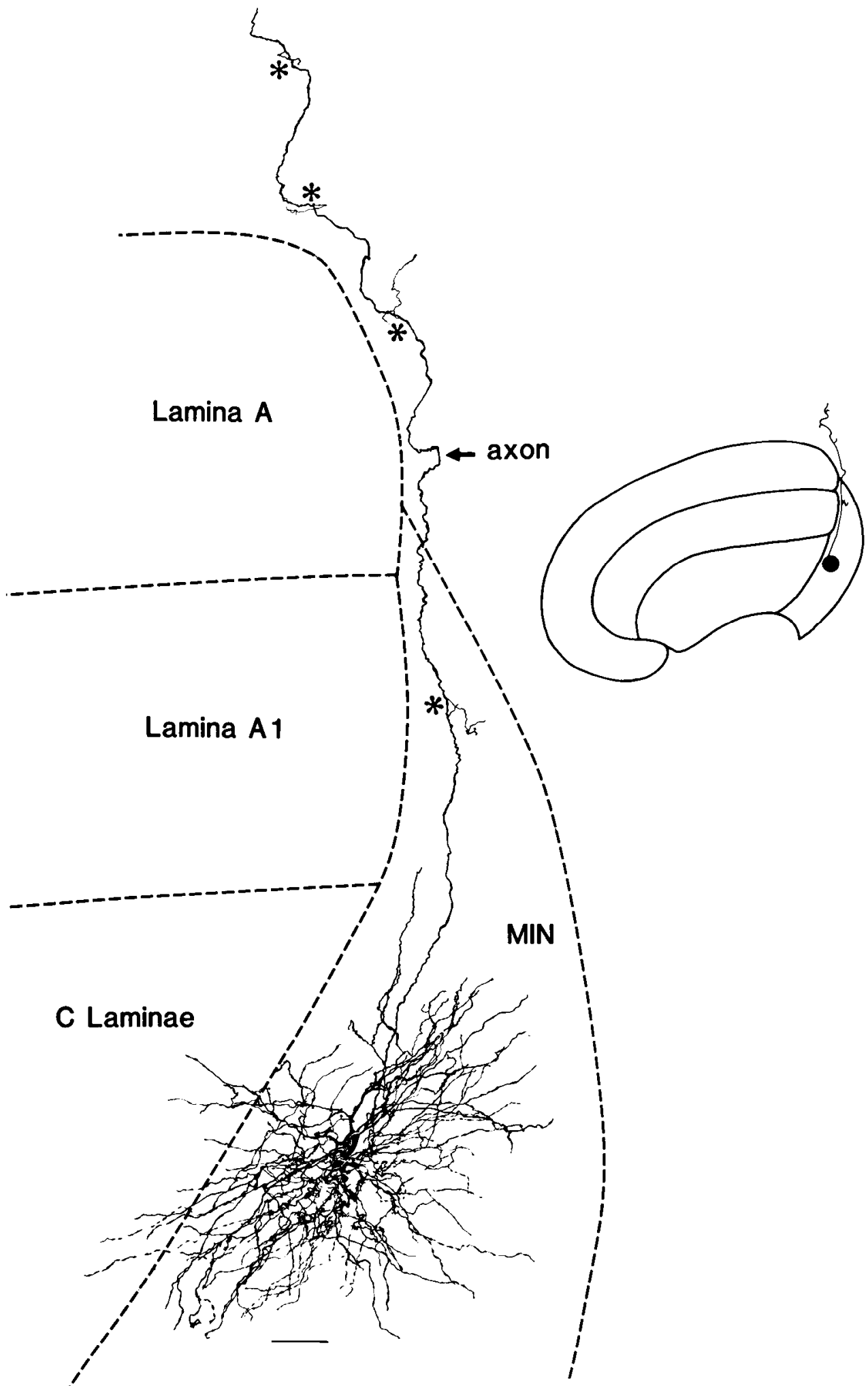

axons traced for a distance within the lateral geniculate nucleus, only 2 gave off intrageniculate collaterals (Fig. 16B). One of these collaterals was located within the MIN and the other in lamina A. Of our sample, only the cell illustrated in Figure 8 had an axon that issued perigeniculate collaterals, and these are further illustrated in Figure $16 \mathrm{C}$. Both intrageniculate and perigeniculate collaterals were characterized by rather fine axon branches possessing simple swellings along their course. Given the extremely fine caliber of these collaterals, it is possible that other collaterals were too fine to detect with the light microscope. Nonetheless, the paucity of axon collaterals of MIN Y-cells contrasts with the common occurrence of these collalerals, particularly perigeniculate collaterals, for $W_{-}, X_{-}$, and $Y$ cells in the A and $C$ laminae (Friedlander et al., 1981; Stanford et al., 1983).

\section{Discussion}

This study was undertaken to identify the neuronal population that comprises laminae 1 and 2 of the MIN and to determine what, 


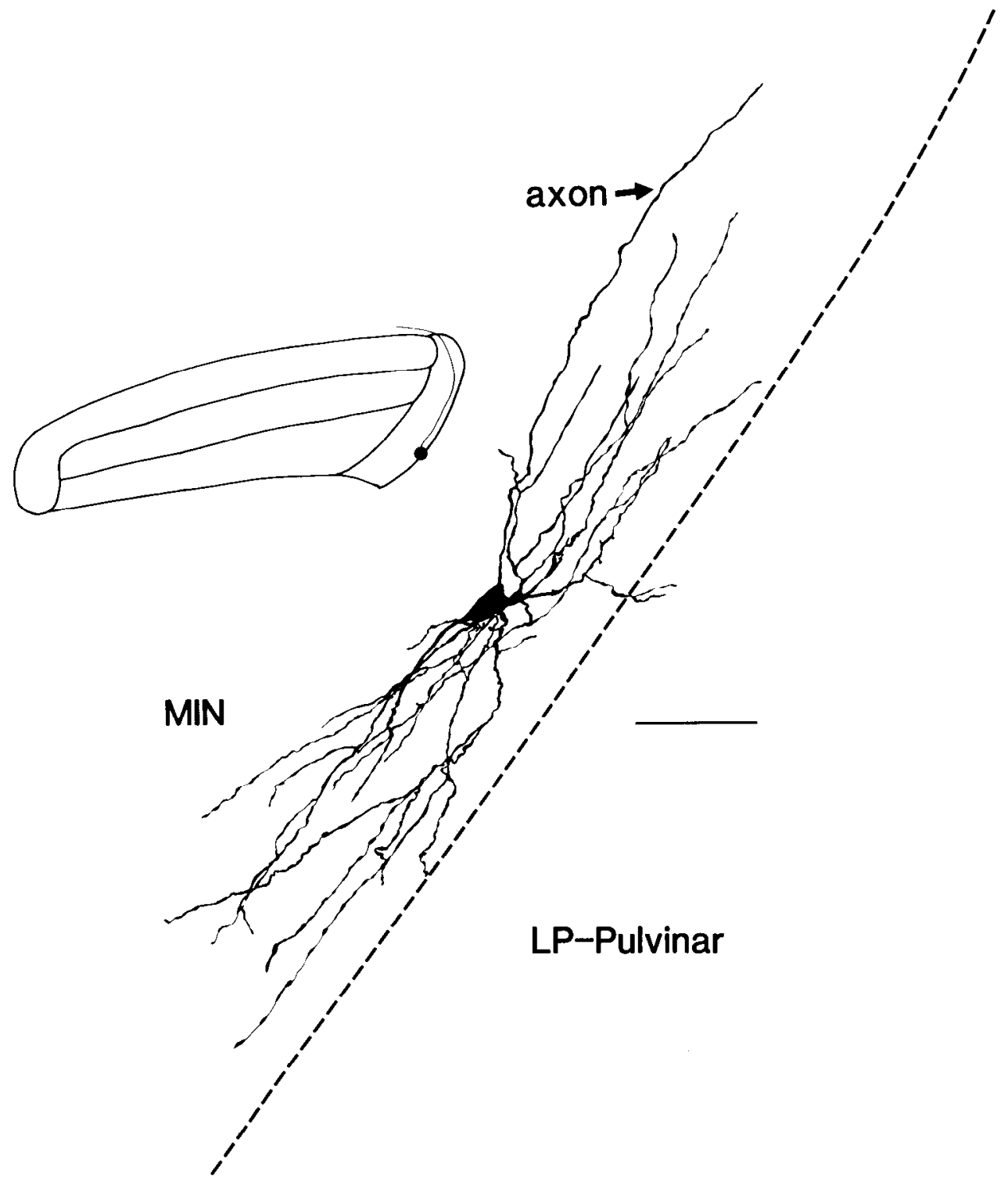

Figure 9. Drawing tube tracing of an MiN $Y$-cell intracellularly filled with HRP. This neuron had a fusiform soma and dendrites oriented in a bipolar fashion. $L P$, lateral posterior. Scale bar, $50 \mu \mathrm{m}$ for main drawing; $1.3 \mathrm{~mm}$ for inset. if any, relationships exist among morphological features, physiological properties, and projection patterns of these MIN neurons. Our data reveal that most, if not all, of these MIN relay neurons comprise a single morphological class that is also a single physiological class of $Y$-cells. Although morphological heterogeneity exists among these relay neurons, we found no compelling evidence to suggest separate neuronal classes. Furthermore, these MIN neurons seem quite similar in structure and physiology to $Y$-cells in the $A$ and $C$ laminae. It is possible that $Y$-cells throughout the lateral geniculate nucleus comprise a single morphological class that exhibits some morphological variability. These and other related issues are discussed in further detail below.

\section{Do laminae 1 and 2 of the MIN contain a single physiological class of relay neuron?}

We unambiguously identified the vast majority of MIN ncurons recorded in laminae 1 and 2 (65 of 70) as $Y$-cells, and, as noted at the beginning of "Results," all of the neurons unambiguously recorded in the MIN may have been $Y$-cells. These findings are in general agreement with earlier electrophysiological reports that $Y$ cells are the predominant neuronal class in the MIN (Mason, 1975; Paimer et al., 1975; Kratz et al., 1978; Dreher and Sefton, 1979).
However, in a recent mapping study (Lee et al., 1984), a ventral and posterior sector of MIN was encountered in which no visual activity was recorded, and this was thought to perhaps contain W-cells. We, too, occasionally passed through small "silent zones" but did not inject neurons there and cannot say with certainty whether these correspond to the unresponsive zorle previously described (Lee et al., 1984). In any case, these may represent small and local concentrations of W-cells that, for some reason, do not respond in our experimental paradigm.

Furthermore, several morphological studies indicate that the MIN is innervated by $X$ - and perhaps $W$-cells from the retina. The strongest evidence for retinal $X$-cell input to the MIN arises from direct evidence obtained from intracellular staining of individual retinogeniculate axons (Sur and Sherman, 1982; but see Bowling and Michael, 1984). Although Y-cell axons provide the overwhelming majority of retinal input to MIN neurons, some $X$-cell innervation has also been observed. However, whereas nearly every $Y$-cell axon innervates the MIN fairly densely, only a small minority of $X$-cells do so, and the $X$-cell arbors in the MIN are exceedingly sparse. Indirect morphological evidence for $W$-cell innervation of the MIN arises from an examination of labcled retinal ganglion cells following injections of HRP into the MIN (Itoh et al., 1981; Rowe and Dreher, 1982). In 
Figure 10. Drawing tube tracings of four representative MiN Y-cells ( $A$ to $D$ ) intracellularly filled with HRP. Note the variation in soma size and dendritic orientation. The cell in $B$ is also shown in Figure $16 A 2$, and the asterisk indicates an axon collateral in lamina A. Scale bar, $50 \mu \mathrm{m}$ for $A$ to $D, 1.0 \mathrm{~mm}$ for insets.
A

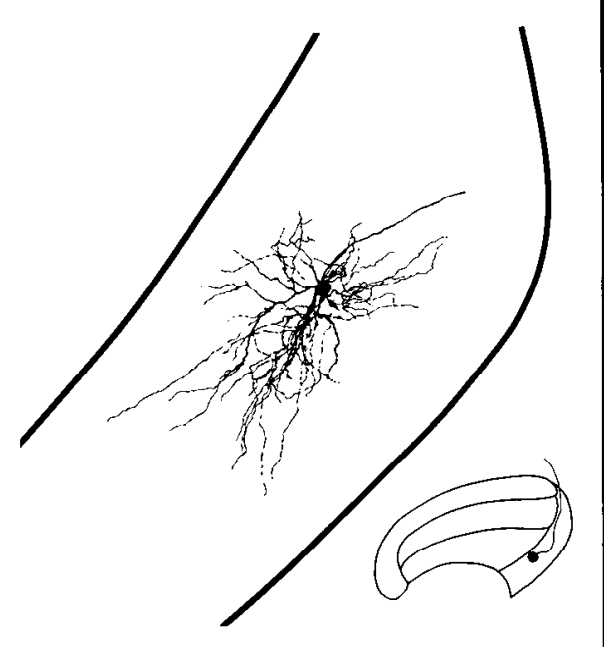

B
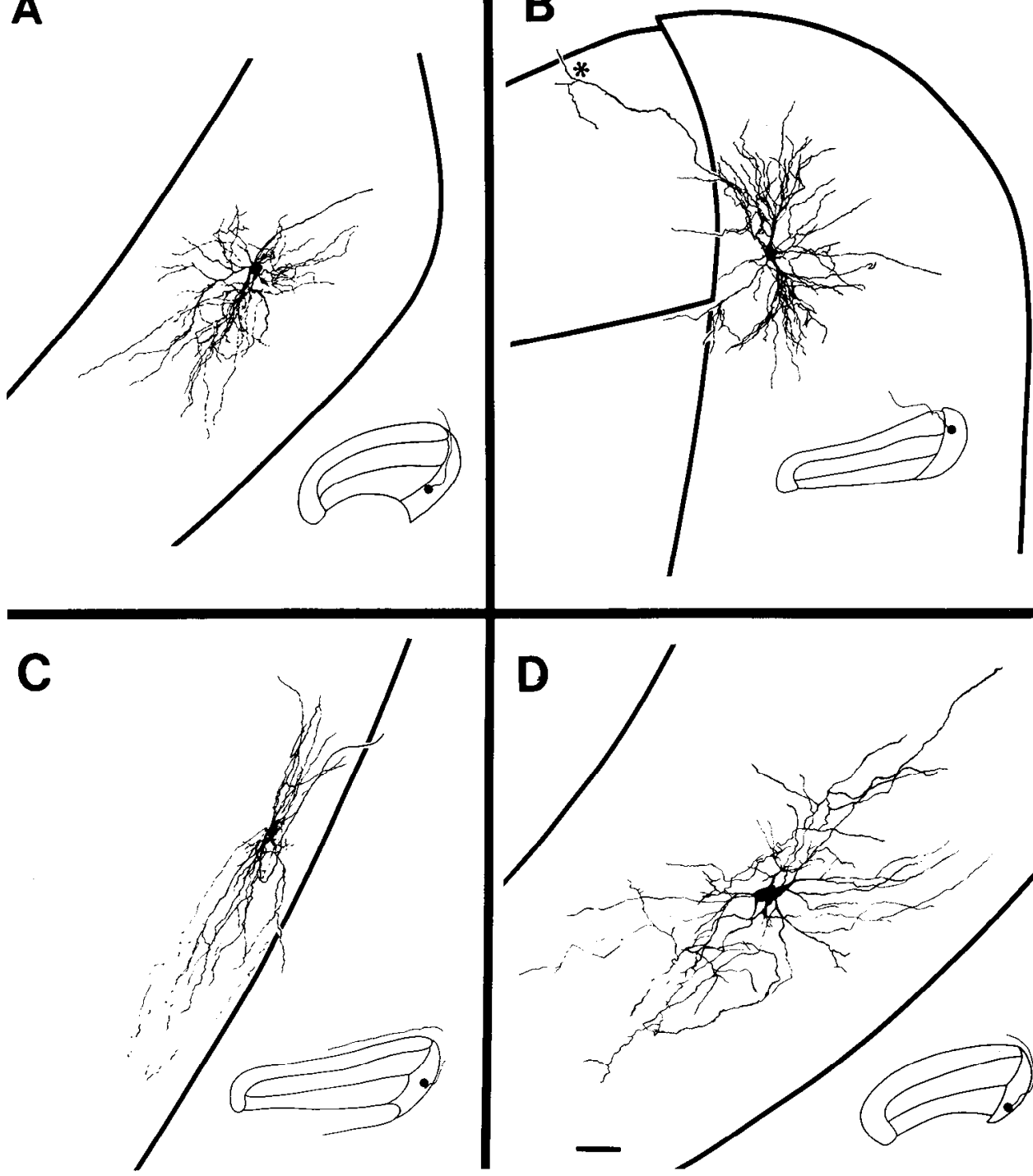

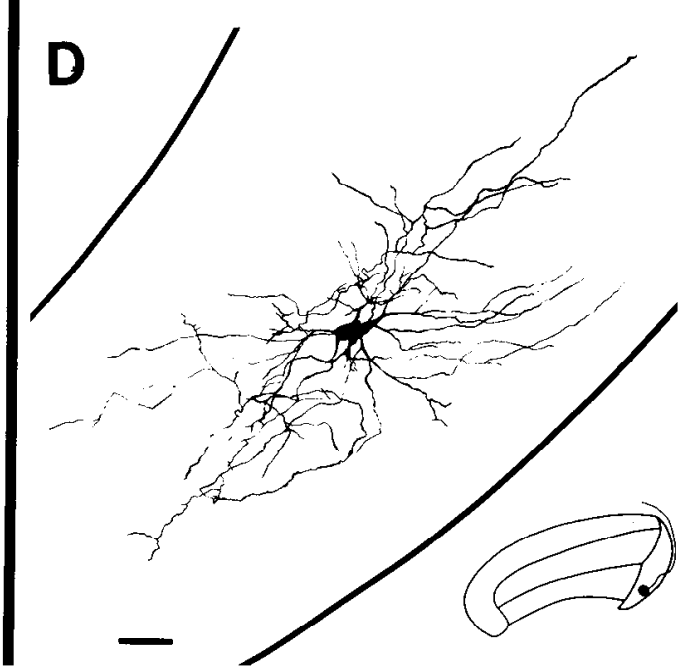

these experiments, both $\alpha$-cells (presumably $Y$-cells) and mediumsized $\gamma$-cells (presumably $W$-cells) were retrogradely labeled from the MIN. Interestingly, no retrogradely labeled $\beta$-cells (presumably $X$ cells) were labeled.

These morphological studies raise the issue of the representative nature of our neuronal sample of injected MIN cells. The physiological and correlated morphological data obtained in this study may have been biased by electrode sampling (Humphrey and Corrie, 1978; Shapley and So, 1980). Although cleariy possible, we can rule out strong sampling biases based on soma size, and this is generally considered to be the chief cause of electrode sampling. The same type of fine-tipped micropipette used in this study was found not to be subject to sampling biases based on cell size in the geniculate A and C laminae (Friedlander et al., 1981; Stanford et al., 1983; Friedlander and Stanford, 1984). Our results in the present study support that conclusion since the soma size distribution of recorded MIN neurons matches the available distribution of Nissl-stained and retrogradely labeled neurons. It also seems unlikely that our electrodes would fail to record available $W$ - and $X$-cell neurons in those portions of the MIN that we extensively studied (laminae 1 and 2), since we routinely recorded $X$ - and $W$-cells in the $A$ and $C$ laminae prior to entering the MIN.

If electrode sampling does not appreciably bias our finding, how can we address the morphological finding of non- $Y$ input into the MIN? Although we do not deny the possible existence of some Wand $X$-cell retinal innervation to the MIN, it is not clear how this would influence MIN cells. The $X$-cell input is so sparse that it might not represent a significant proportion of retinal input to individual MIN neurons. Although Rowe and Dreher (1982) argue that the ganglion cell input to the MIN is roughly equally divided between $W$ - and $Y$ cells, this does not imply equal numbers of synapses from the two cell classes. For instance, although the retinal $X$ - to $Y$-cell ratio that innervates the $A$ laminae is 10 to $20: 1$, the $X$ - to $Y$-cell ratio of retinogeniculate synapses and postsynaptic cells is closer to $2: 1$ (Friedlander et al., 1981; Friedlander and Stanford, 1984). This is because of the much more extensive arbors of $Y$-cell axons than of X-cell axons (Sur and Sherman, 1982; Bowling and Michael, 1984). Our preliminary and incomplete evidence suggests that $W$-cell axon arbors, at least in the $C$ laminae, are even more restricted than are $X$-cell arbors. Thus, the relative number of $W$-cell synapses in the MIN may be quite low compared to $Y$-cell synapses. It is conceivable that every MIN neuron receives mixed input from many $Y$-cell synapses and only a few $W$-cell (and perhaps $X$-cell) synapses, and the physiological tests we have used can reveal only the $Y$-cell input.

The issue of whether the MIN contains appreciable numbers of $W$ - and $X$-cells is far from settled. Our data suggest that the 


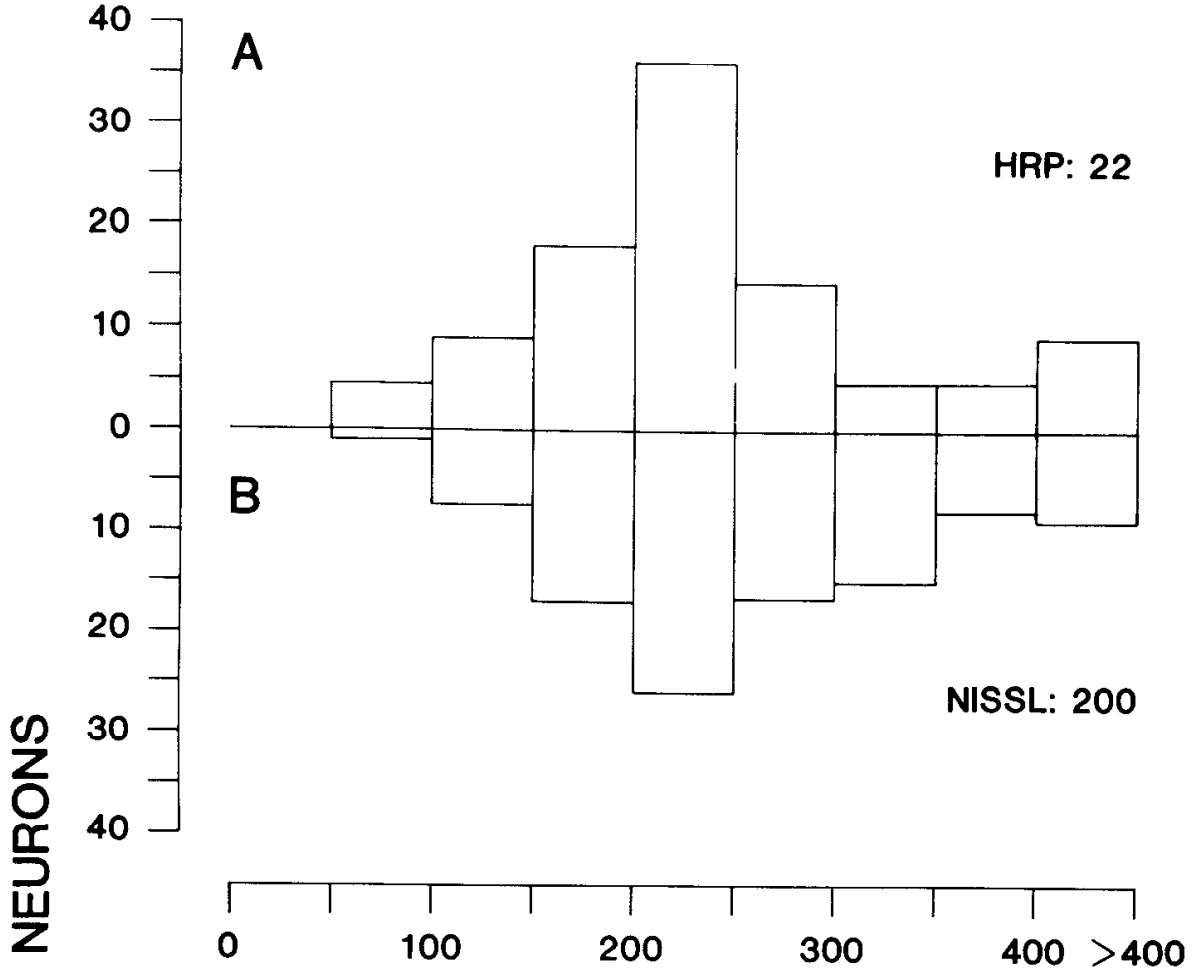

แ

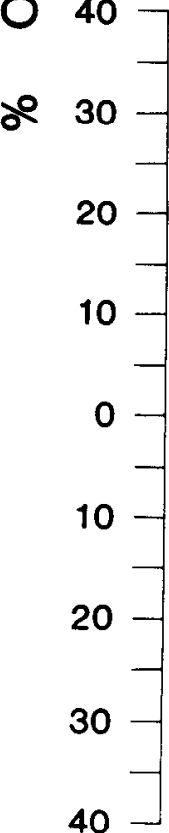

C<smiles>CCC</smiles><smiles>CCC</smiles>

AREA LS: 30
AREA 17: 35

AREA 18: 50
Figure 11. Soma size distribution of MIN relay neurons. $A$, Soma size distribution of 22 MIN Y-cells injected with HRP. B, Soma size distribution of 200 neurons from adjacent Nissl-stained sections. $C$ and $D$, Soma size distribution of 165 neurons retrogradely labeled following HRP injections into cortical areas $17,18,19$, and the lateral suprasylvian (LS) cortex. The histograms of $C$ and $D$ represenl reanlalyzed data from Raczkowski and Rosenquist (1983)

AREA 19: 50

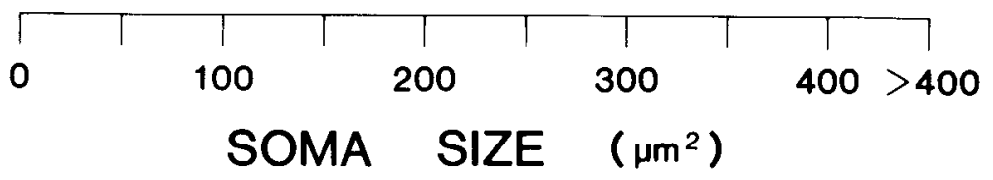

overwhelming majority of MIN neurons are Y-cells and that the MIN can thus be considered as a fairly homogeneous $Y$-cell population. However, in view of the retinal ganglion cell populations that seem to innervate the MIN, one of two conclusions seems likely: either we have not adequately sampled MIN neurons other than $Y$-cells or each MIN cell receives its major retinal input from $Y$-cells and a subliminal input from $\mathrm{W}$ - and/or X-cells.
Do laminae 1 and 2 of the MIN contain a single morphological class of relay neuron?

Morphology of individual dendrites. Dendritic features have been prominent in the morphological classification of neurons in the $A$ and $C$ laminae specifically and in many other portions of the central nervous system more generally (Lorente de No, 1938; O'Leary, 

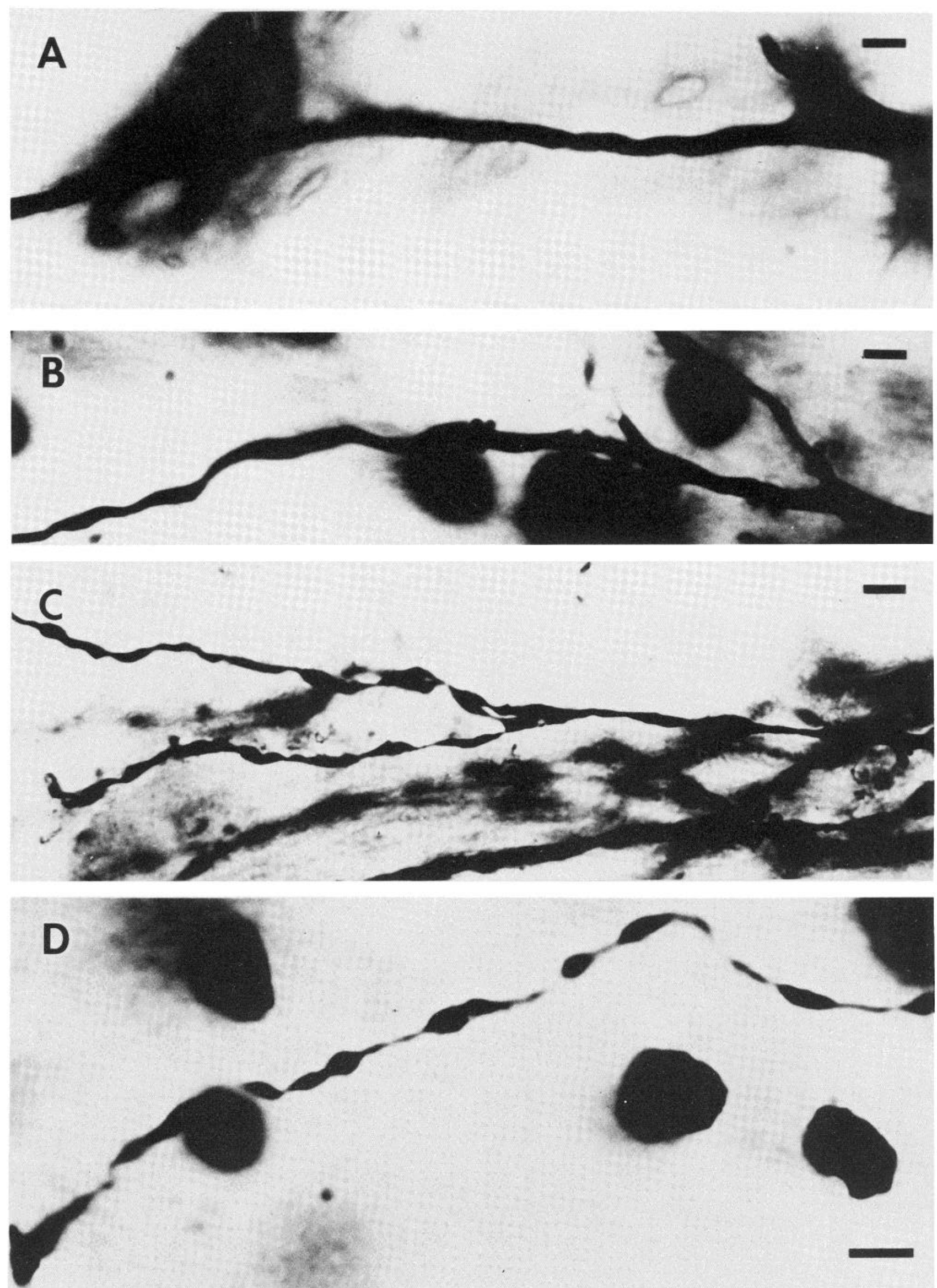

Figure 12. Photomicrographs of representative dendrites from MIN Y-cells. $A$, Smooth, primary dendrite. $B$, Varicose, secondary dendrite. $C$ and $D$, Beaded, secondary dendrites. Scale bars, $1 \mu \mathrm{m}$. 

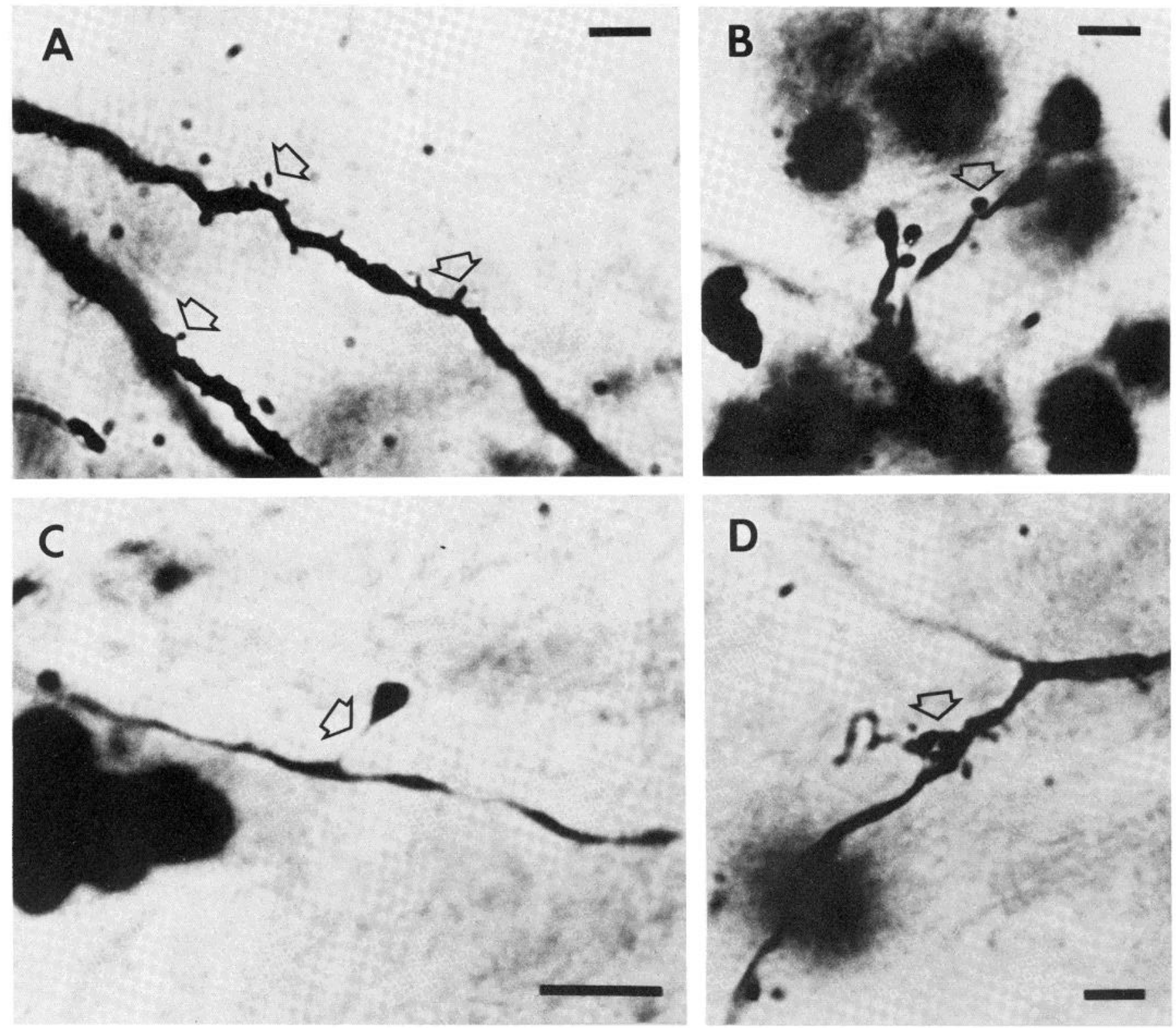

Figure 13. Photomicrographs of representative dendritic specializations (indicated by arrows) from MIN Y-cells. A, Hair-like processes with no visible swelling on the end. $B$, Spherical appendages with no visible stalk. $C$, An appendage with a long slender stalk and a spherical, swollen terminal. $D$, Grapelike appendages near dendritic branch point. Scale bars, $1 \mu \mathrm{m}$.

1941; Guillery, 1966; Friedlander et al., 1981; Hitchcock and Hickey, 1983; Stanford et al., 1983). These features figure prominently in our classification of MIN cells. This is a reasonable starting point since morphological differences among dendrites almost certainly reflect differences in afferent connections (Fox and Barnard, 1957). Furthermore, the effect that a particular afferent connection may have on a neuron may be predicated not only by the portion of dendrite it contacts, but also upon the geometry of the postsynaptic specialization being contacted (Rall and Rinzel, 1973; Rall, 1977). Thus, it seems likely that the morphology of dendrites is of functional importance and a relevant parameter to be used for classification.

A number of morphological characteristics are common to the MIN neurons. Dendrites are typically straight and fairly smooth (i.e. free of appendages), and many of them cross laminar borders. Dendritic appendages, when present, are usually simple spine-like structures, although some dendrites possess grape-like clusters of appendages near branch points. Furthermore, although most proxi- mal dendrites are fairly straight, more distal dendrites can be varicose or (in extreme cases) beaded. Although appendages clustered near branch points and varicose or beaded dendritic segments are features that have figured in prior cell classification schemes, it is important to note that each of these features have been recognized within the separate $W_{-}, \mathrm{X}$-, and $\mathrm{Y}$-cell classes in the $\mathrm{A}$ and $\mathrm{C}$ laminae (Friedlander et al., 1981; Stanford et al., 1983). Obviously, these features have not yet proven to be reliable indicators of a particular functional class of neuron.

Despite the variability seen in dendritic structure, we saw no compelling evidence to suggest more than one class of neuron and instead interpret this tentatively as heterogeneity within a single class. Similar variability was noted for the $Y$-cells of the $A$ and $C$ laminae (Friedlander et al., 1981). Indeed, Y-cells in the MIN and in the $A$ and $C$ laminae appear to share many, if not most, morphological features of individual dendrites (cf. Friedlander et al., 1981; Stanford et al., 1983). 

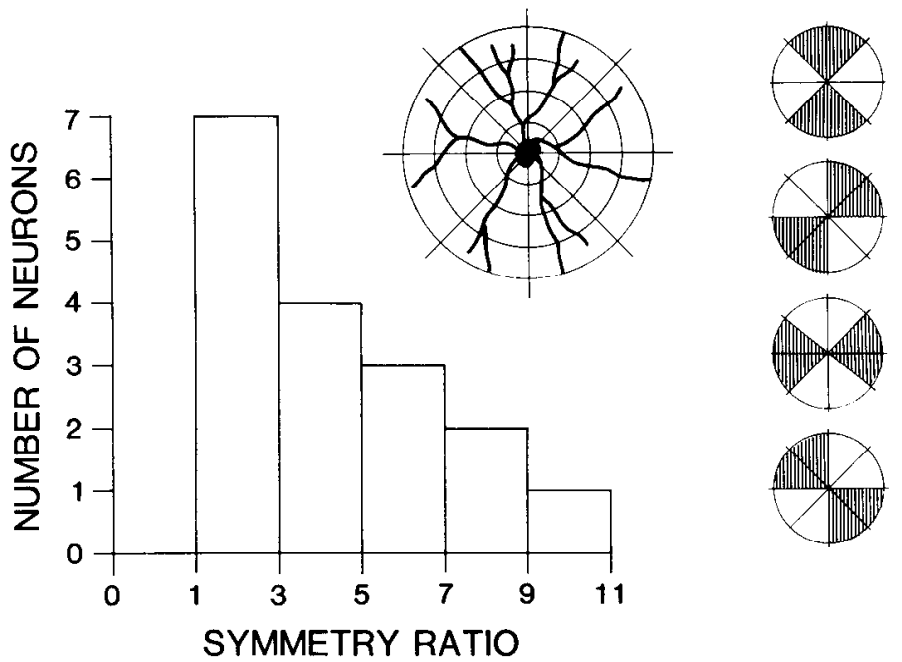

Figure 14. Number of dendritic intersections with four concentric circles spaced $50 \mu \mathrm{m}$ apart and centered on the soma. The insets illustrate the manner in which the concentric circles were divided into eight compartments. We identified which two opposite pairs of compartments (vertical hatching) of the four possible combinations contained the most intersections to obtain what we term a "symmetry ratio" (see the text for details). A continuum of symmetry ratios exists.

Morphology and geometry of dendritic arbors. The geometry of dendritic arbors differs distinctively among the $\mathrm{W}$-, $\mathrm{X}$-, and $\mathrm{Y}$-cell classes in the A and C laminae (Friedlander et al., 1981; Stanford et al., 1983), which suggests that dendritic shape is of some functional significance. $Y$-cells in the $A$ and $C$ laminae exhibit dendrites that occupy roughly spherical arbors, and some dendrites of each neuron cross laminar borders. MIN Y-cell arbors are more variable in shape, ranging in a continuum from spherical to ovoid (Fig. 10), and translaminar dendrites are also common among MIN Y-cells. The only obvious difference between MIN $Y$-cells and those of the $A$ and $C$ laminae is the occurrence of relatively bipolar dendritic arbors common to the former but not the latter. Our measures of neuronal rosponse properties suggest no obvious functional correlation for this difference, but this may simply reflect an inadequacy in our battery of electrophysiological tests. Thus, although we can emphasize this morphological difference between MIN Y-cells and those of the $A$ and $C$ laminae, we cannot address its functional significance, if any.

Morphology of axons. Collaterals originating from the axons of MIN Y-cells were rarely observed. In contrast, many more $Y$-cells in the $A$ and $C$ laminae provide intrageniculate collaterals, and nearly all innervate the perigeniculate nucleus with fairly extensive collaterals (Friedlander et al., 1981). This obvious difference in perigeniculate innervation represents the sole major distinction we observed between $Y$-cells of the MIN and those of the A and C laminae.

Perigeniculate cells, which are innervated by axon collaterals of relay cells (as well as by collaterals of corticogeniculate axons) in turn project their axons back onto relay cells in the $A$ and $C$ laminae (Dubin and Cleland, 1977; Ahlsen and Lindstrom, 1978; Lindstrom, 1982; Ahlsen et al., 1984). Interestingly, our preliminary unpublished observations of several HRP-filled perigeniculate neurons suggest that their projection may be limited to the $A$ and $C$ laminae and may not extend into the MIN. The perigeniculate nucleus thus seems to represent a somewhat displaced portion of the thalamic reticular complex that is involved in feedback circuits only with neurons of the $A$ and $C$ larnirlae. This may explain some of the differences in synaptology between the MIN and A laminae (Wilson, 1983). Also, perhaps MIN cells engage in analogous circuits with another, as yet unspecified portion of the thalamic reticular complex. This implies that axons from the MIN, while passing through this complex en route to cortex, would emit collaterals. Unfortunately, we could not trace axons from MIN cells sufficiently dorsally to test this possibility. We can only conclude that, if MIN Y-cells engage in feedback circuits involving the thalamic reticular complex, they engage a different portion of this complex from that of $Y$-cells of the $A$ and $C$ laminae, which interact solely with the perigeniculate nucleus.

\section{Functional signi, jance of the MIN}

It is not yet possible to assign a specific functional role to the MIN, but three features of its functional organization seem worth emphasizing. First, MIN relay neurons represent a practically pure $Y$ cell population, although as noted abovc, many may receive $W$ - or $X$-cell input that is subliminal to our tests. Second, although $Y$-cells in the MIN and $A$ and $C$ laminae project to some of the same areas of cerebral cortex, those in the $A$ and $C$ laminae mainly innervate areas 17 and 18 whereas the MIN mainly innervates area 19 and areas of the lateral suprasylvian cortex (Tong et al., 1982; Raczkowski and Rosenquist, 1983). Third, receptive fields of MIN Ycells tend to be larger than those of $Y$-cells in the $A$ and $C$ laminae (Kratz et al., 1978; Dreher and Sefton, 1979).

The significance of the $Y$-cell relay in the MIN may relate to a recent suggestion for the functional significance of the $X$ - and $Y$-cell pathways: the $Y$-cell pathway is involved in a basic analysis of spatial patterns whereas the $X$-cell pathway adds spatial detail to this analysis (Sherman, 1979, 1985). Thus, Y-cells are relatively more responsive to lower spatial frequencies, and $X$-cells are more responsive to higher ones (Sherman, 1979, 1985; Lehmkuhle et al., 1980; Troy, 1983). The MIN, then, might provide this essential information to many extrastriate areas. Indeed, this relay might underly the excellent form vision seen in cats with removal of area

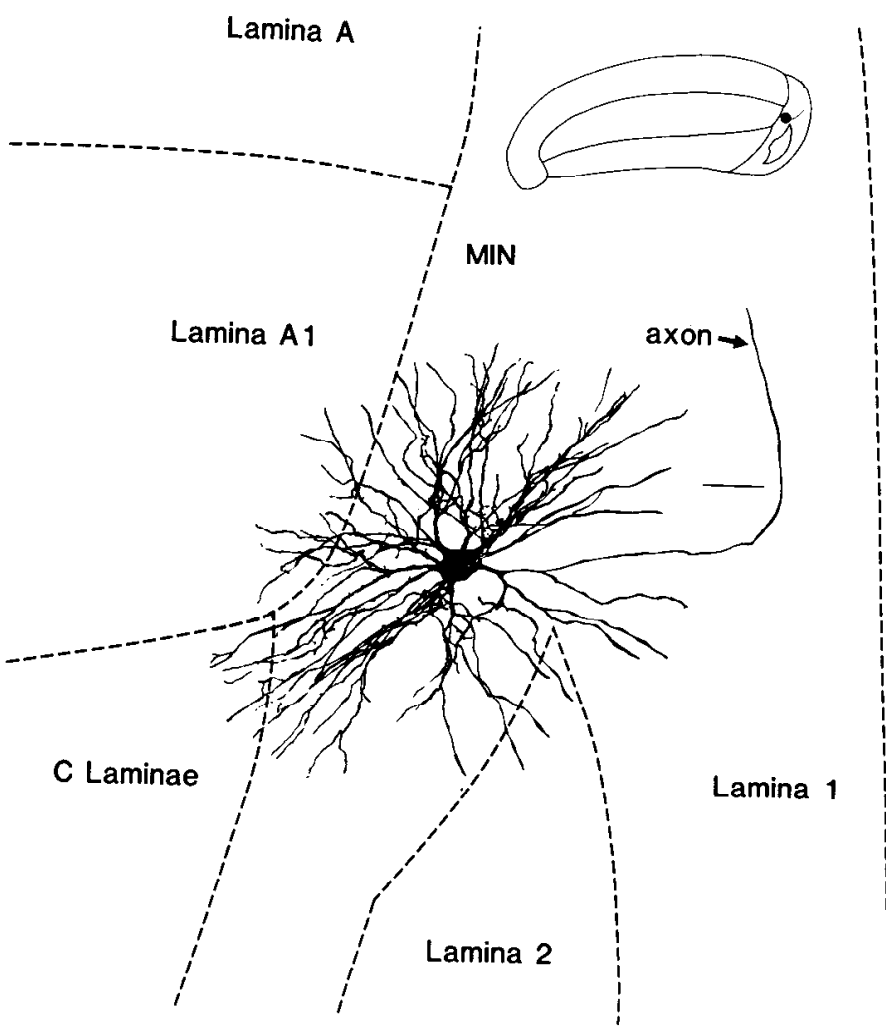

Figure 15. Drawing tube tracings of an MIN Y-cell intracellularly filled with HRP to show the relationship between dendritic arbors and individual laminae within the lateral geniculate nucleus. The laminar borders within the MIN were identified by autoradiography following intraocular injection of tritiated leucine into the contralateral eye. Note that, although the soma and most dendrites are in lamina 1, which is appropriate for the cell's receptive field in the contralateral eye, some dendrites cross into laminae A1 and 2, which are innervated by the ipsilateral eye. Scale bar, $50 \mu \mathrm{m}$ for main drawing; $1.0 \mathrm{~mm}$ for inset. 
The Journal of Neuroscience

A
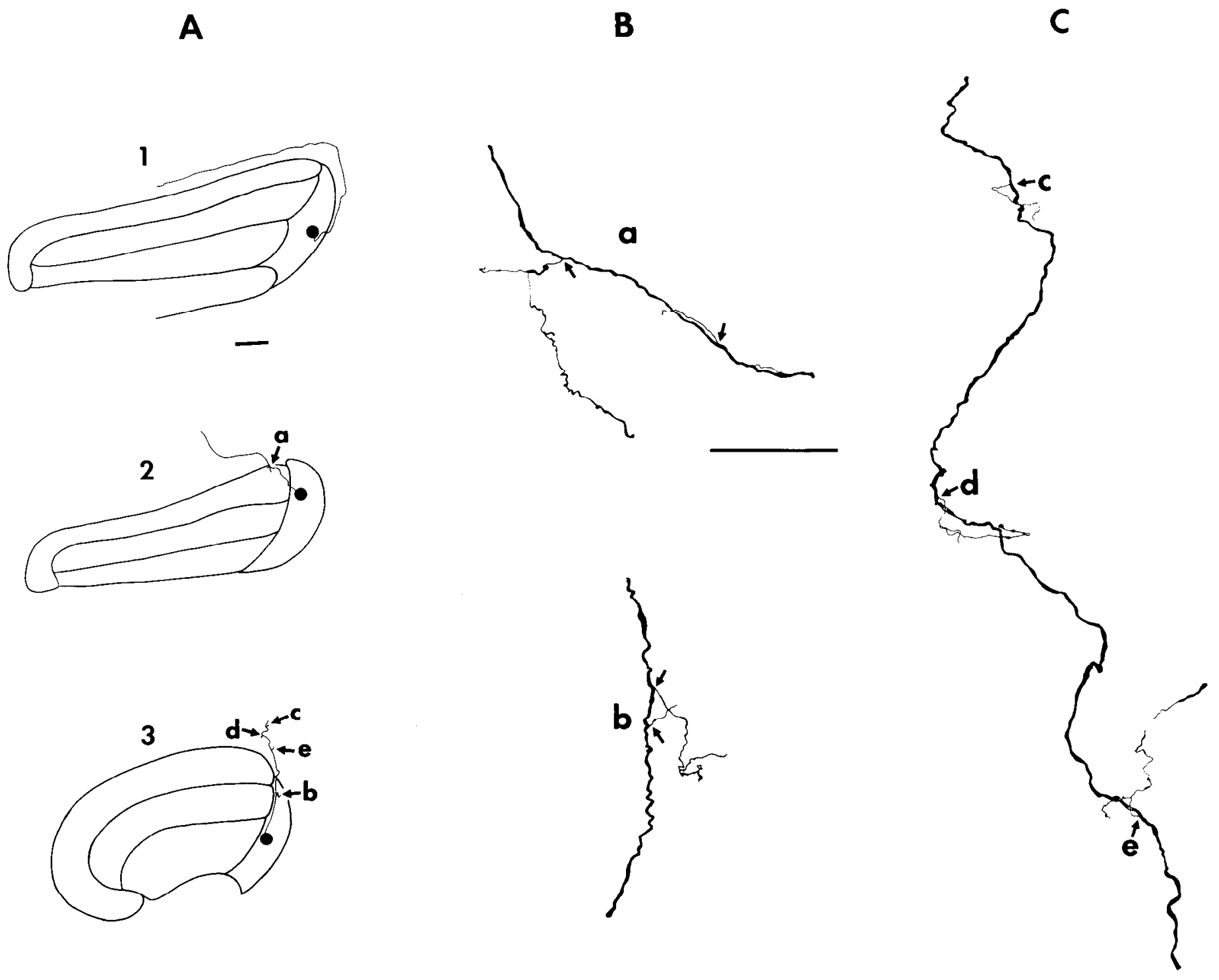

Structure/Function Analysis of MIN Cells

2717

Figure 16. Drawing tube tracings of axon trajectories and collaterals of MIN Y-cells intracellularly filled with HRP. A, Lower power drawings of the lateral geniculate nucleus showing the location of three individual MIN neurons (-) and the course of their axons. Cell 1 is also illustrated in Figure $10 \mathrm{C}$, cell 2 is also illustrated in Figure 10B, and cell 3 is also illustrated in Figure 8. The regions of collaterals indicated by arrows and lower case letters (a to e) are shown in higher power in $B$ and $C$. $B$. Higher power drawings showing details of intrageniculate collaterals. $C$, Higher power drawings showing details of perigeniculate collaterals. Scale bars: $A, 500 \mu \mathrm{m} ; B$ and $C, 50 \mu \mathrm{m}$.

17 and large portions of area 18 (Berkley and Sprague, 1979; Lehmkuhle et al., 1982).

The larger receptive fields of MIN Y-cells compared to those in the $\mathrm{A}$ and $\mathrm{C}$ laminae presumably reflect more convergent input from retinogeniculate $Y$-cell axons to these MIN neurons. Such convergence permits spalial and temporal summation, which might make these MIN Y-cells more sensitive to visual stimuli at the expense of spatial resolution than are other geniculate $Y$-cells. The MIN, then, could represent a special high sensitivity, low resolution relay to extrastriate cortex. This can be contrasted to the A laminae, in which $X$ - and $Y$-cell relays would represent a less sensitive, higher resolution relay to areas 17 and 18 . A related argument of a particularly photicsensitive relay through the MIN was recently proposed by Lee et al. (1984) based on their observation that the tapetum lucidum region of retina was greatly emphasized in the retinotopic map of the MIN.

\section{Conclusions}

All of the available physiological and morphological data suggest that $Y$-cells of our sample from laminae 1 and 2 of the MIN form a single class. Although our intracellularly labeled neurons were all $Y$ cells, their morphological features were not noticeably different from those of other MIN neurons as determined either by Nissl stains or by retrograde labeling with HRP from the optic radiations or visual cortex. In other words, if a prominent population of W- or X-cells existed in laminae 1 and 2 of the MIN that could not be recorded by our electrodes, these cells would not be morphologically very different from MIN $Y$-cells. Given the dramatic differences among $W$-, $X$-, and $Y$-cells in the $A$ and $C$ laminae, this seems unlikely. We thus conclude that the vast majority of neurons in laminae 1 and 2 of the MIN are $Y$-cells with morphological features roughly equivalent to those of $Y$-cells in the $A$ and $C$ laminae. However, we found two morphological differences between MIN $Y$-cells and those of the $A$ and $C$ laminae. First, $Y$-cells with bipolar dendritic arbors are common in the MIN but not in the $A$ and $C$ laminae. Second, $Y$-cells in the $A$ and $C$ laminae seem intimately involved in perigeniculate circuitry whereas MIN Y-cells are not.

\section{References}

Ahlsen, G., and S. Lindstrom (1978) Projection of perigeniculate neurones to the lateral geniculate body in the cat. Neurosci. Lett. Suppl. 1: S367.

Ahlsen, G., S. Lindstrom, and F. -S. Lo (1984) Inhibition from the brain stem 
of inhibitory interneurones of the cat's dorsal latcral geniculatc nuclcus. J. Physiol. (Lond.) 347: 593-609.

Berkley, M. A., and J. M. Sprague (1979) Striate cortex and visual acuity functions in the cat. J. Comp. Neurol. 187: 679-702.

Bowling, D. B., and C. R. Michael (1984) Terminal patterns of single, physiologically characterized optic tract fibers in the cat's lateral geniculate nucleus. J. Neurosci. 4: 198-216.

Dreher, B., and A. J. Sefton (1979) Properties of neurons in cat's dorsa lateral geniculate nucleus: A comparison between medial interlaminar and laminated parts of the nucleus. J. Comp. Neurol. 183: 47-64.

Dubin, M. W., and B. G. Cleland (1977) The organization of visual inputs to interneurons of the lateral geniculate nucleus of the cat. J. Neurophysiol. 40: 410-427.

Friedlander, M. J., and L. R. Stanford (1984) Effects of monocular deprivation on the distribution of cell typos in the LGNd: A sampling study with finetipped micropipettes. Exp. Brain Res. 53: 451-461.

Friedlander, M. J., C. -S. Lin, L. R. Stanford, and S. M. Sherman (1981) Morphology of functionally identified neurons in the lateral geniculate nucleus of the cat. J. Neurophysiol. 46: 80-129.

Fox, C. A., and J. W. Barnard (1957) A quantitative study of the Purkinje cell dendritic branchlets and their relationship to afferent tibers. J. Anat. 97. 299-313.

Guillery, R. W. (1966) A study of Golgi preparations from the dorsal lateral geniculate nucleus of the adult cat. J. Comp. Neurol. 128: 21-50.

Guillery, R. W., E. E. Geisert, Jr., E. H. Polley, and C. A. Mason (1980) An analysis of the retinal afferents to the cat's medial interlaminar nucleus and to its rostral thalamic extension, the "geniculate wing". J. Comp. Neurol. 194: $117-192$

Hitchcock, P. F., and T. L. Hickey (1983) Morphology of C-laminae neurons in the dorsal lateral geniculate nucleus of the cat: A Golgi impregnation study. J. Comp. Neurol. 220: 137-146.

Humphrey, D. R., and W. S. Corrie (1978) Properties of pyramidal tract neuron system within a functionally defined subregion of primate motor cortex. J. Neurophysiol. 41: 216-243.

Itoh, K., M. Conley, and I. T. Diamond (1981) Different distributions of large and small retinal ganglion cells in the cat after HRP injections of single layers of the lateral geniculate body and the superior colliculus. Brain Res. 207: $147-152$

Kinston, W. J., M. A. Vadas, and P. O. Bishop (1969) Multiple projection of the visual field to the medial portion of the dorsal lateral geniculate nucleus and the adjacent nuclei of the thalamus of the cat. J. Comp. Neurol. 136: 295-315.

Kratz, K. E., S. V. Webb, and S. M. Sherman (1978) Studies of the cat's medial interlaminar nucleus: A subdivision of the dorsal lateral geniculate nucleus. J. Comp. Neurol. 181: 601-614.

Lee, C., J. G. Malpeli, H. D. Schwark, and T. G. Weyand (1984) Cat medial interlaminar nucleus: Retinotopy, relation to tapetum and implications for scotopic vision. J. Neurophysiol. 52: 848-869.

Lehmkuhle, S., K. E. Kratz, S. C. Mangel, and S. M. Sherman (1980) Spatial and temporal sensitivity of $X$ - and $Y$-cells in dorsal lateral geniculate nucleus of the cat. J. Neurophysiol. 43: 520-541.

Lehmkuhle, S., K. E. Kratz, and S. M. Sherman (1982) Spatial and temporal sensitivity of normal and amblyopic cats. J. Neurophysiol. 48: 372-387.

Lindstrom, S. (1982) Synaptic organization of inhibitory pathways to principal cells in the lateral geniculate nucleus of the cat. Brain Res. 234: 447-453.

Lorente de No, R. (1938) The cerebral cortex: Architecture, intracortical connections and motor projections. In Physiology of the Nervous System,
J. F. Fulton, ed., pp. 291-325, Oxford University Pross, London.

Mangel, S. C., J. R. Wilson, and S. M. Sherman (1983) Development of neuronal response properties in the cat dorsal lateral geniculate nucleus during monocular deprivation. J. Neurophysiol. 50: 240-264.

Mason, R. (1975) Cell properties in the medial interlaminar nucleus of the cat's lateral geniculate complex in relation to the transient/sustained classification. Exp. Brain Res. 22: 32/-329.

O'Leary, J. L. (1941) Structure of the area striata of the cat. J. Comp. Neurol. 75: $131-164$

Palmer, L. A., A. C. Rosenquist, and R. Tusa (1975) Visual receptive fields in lam LGNd, MN and PN of the cat. Soc. Neurosci. Abstr. 1:54

Raczkowski, D., and A. C. Rosenquist (1983) Connections of the multiple visual cortical areas with the lateral posterior-pulvinar complex and adjacent thalamic nuclei in the cat. J. Neurosci. 3: 1912-1942

Raczkowski, D., and S. M. Sherman (1983) Morphological and functional analysis of single neurons in the medial interlaminar nucleus (MIN) of the cat's lateral geniculate nucleus. Soc. Neurosci. Abstr. 9: 1046.

Rall, W. (1977) Core conductor theory and cable properties of neurons. In Handbook of Physiology. Section 1: The Nervous System, Vol. I, Part 1: Cellular Biology of Neurons, E. R. Kandel, ed., pp. 39-97, American Physiological Society, Bethesda, MD.

Rall, W., and J. Rinzel (1973) Branch input resistance and steady attenuation for input to one branch of a dendritic neuron model. Biophys. J. 13:648688.

Rosenquist, A. C., S. B. Edwards, and L. A. Paimer (1974) An autoradiographic study of the projections of the dorsal lateral geniculate nucleus and the posterior nucleus in the cat. Brain Res. 80: 71-93.

Rowe, M. H., and B. Dreher (1982) Retinal W-cell projections to the media interlaminar nucleus in the cat: Implications for ganglion cell classification. J. Comp. Neurol. 204: 117-133.

Sanderson, K. J. (1971) The projection of the visual field to the lateral geniculate and medial interlaminar nuclei in the cat. J. Comp. Neurol. 143 $101-118$

Shapley, R., and $Y$. T. So (1980) Is there an effect of monocular deprivation on the proportions of $X$ and $Y$ celis in the cat lateral geniculate nucleus? Exp. Brain Res. 39: 41-48.

Sherman, S. M. (1979) The functional significance of $X$ and $Y$ cells in norma and visually deprived cats. Trends Neurosci. 2: 192-195.

Sherman, S. M. (1985) Functional organization of the W-, X-, and Y-cell pathways: A review and hypothesis. In Progess in Psychobiology and Physiological Psychology, J. M. Sprague and A. N. Epstein, eds., pp. 233-314, Vol. 11, Academic Press, Inc., New York.

Stanford, L. R., M. J. Friedlander, and S. M. Sherman (1983) Morphological and physiological properties of geniculate $W$-cells of the cat: A comparison with X-and Y-cells. J. Neurophysiol. 50: 582-608.

Sur, M., and S. M. Sherman (1982) Retinogeniculate terminations in cats: Morphological differences between $X$ and $Y$ cell axons. Science 218: 389 391.

Tong, L., R. Kalil, and P. D. Spear (1982) Thalamic projections to visual areas of the middle suprasylvian sulcus in the cat. J. Comp. Neurol. 212: 103117.

Troy, J. B. (1983) Spatial contrast sensitivities of $X$ and $Y$ type neurones in the cat's dorsal lateral geniculate nucleus. J. Physiol. (Lond.) 344: $399-$ 417

Wilson, J. R. (1983) An electron microscopic comparison of the medial interlaminar nucleus and the A laminae of the dorsal lateral geniculate nucle.us of the cat. J. Comp. Neurol. 212: 89-101. 